This item was submitted to Loughborough's Research Repository by the author.

Items in Figshare are protected by copyright, with all rights reserved, unless otherwise indicated.

\title{
Analysis and comparative study of different converter modes in modular second-life hybrid battery energy storage systems
}

PLEASE CITE THE PUBLISHED VERSION

http://dx.doi.org/10.1109/JESTPE.2015.2460334

PUBLISHER

(C) IEEE

VERSION

AM (Accepted Manuscript)

LICENCE

CC BY-NC-ND 4.0

\section{REPOSITORY RECORD}

Mukherjee, Nilanjan, and Dani Strickland. 2019. "Analysis and Comparative Study of Different Converter Modes in Modular Second-life Hybrid Battery Energy Storage Systems". figshare.

https://hdl.handle.net/2134/24952. 


\title{
Analysis and Comparative Study of Different Converter Modes in Modular Second Life Hybrid Battery Energy Storage Systems
}

\author{
Nilanjan Mukherjee, Member, IEEE, Dani Strickland
}

\begin{abstract}
The use of ex-transportation battery system (i.e. second life EV/HEV batteries) in grid applications is an emerging field of study. A hybrid battery scheme offers a more practical approach in second life battery energy storage systems because battery modules could be from different sources/ vehicle manufacturers depending on the second life supply chain and have different characteristics e.g. voltage levels, maximum capacity and also different levels of degradations. Recent research studies have suggested a dc-side modular multilevel converter topology to integrate these hybrid batteries to a grid-tie inverter. Depending on the battery module characteristics, the dc-side modular converter can adopt different modes such as boost, buck or boost-buck to suitably transfer the power from battery to the grid. These modes have different switching techniques, control range, different efficiencies, which give a system designer choice on operational mode. This paper presents an analysis and comparative study of all the modes of the converter along with their switching performances in detail to understand the relative advantages and disadvantages of each mode to help to select the suitable converter mode. Detailed study of all the converter modes and thorough experimental results based on a multi-modular converter prototype based on hybrid batteries has been presented to validate the analysis.
\end{abstract}

Index Terms - Second life battery energy storage systems (SLBESS), hybrid battery energy storage system (HBESS), boostmultilevel buck converter, multiple battery types, comparison

\section{NOMENCLATURE}

$S_{i}, S_{i i}$

$T_{i}, T_{i i}$

$V_{\text {batt }, i}$

$v_{\text {batt }, i}$

$i_{\text {batt }, i}{ }^{*}$

$i_{\text {batt }, i}$

Manuscript received February 20, 2015; revised April 24, 2015; June 20 , 2015; accepted July 18, 2015. This work was supported by the Engineering and Physical Sciences Research Council (EPSRC), U.K., under Grant $\mathrm{EP} / 1008764 / 1$.

Copyright (c) 2015 IEEE. Personal use of this material is permitted. However, permission to use this material for any other purposes must be obtained from the IEEE by sending a request to pubs-permissions@ieee.org

N. Mukherjee is with the School of Electronic, Electrical and Systems Engineering, University of Birmingham, Birmingham B15 2TT, UK (Email: n.mukherjee@ bham.ac.uk)

D. Strickland is with the Dept. of Electrical, Electronic and Power Engineering, Aston University, Birmingham, B4 7ET, U.K (Email: D.STRICKLAND@aston.ac.uk )
$I_{\text {batt }, i}$

$v_{d c, i}$

$V_{d c, i}$

$v_{d c, i}$

$V_{d c}$

$v_{d c}$

$v_{d c}^{*}$

$I_{d c}$

$i_{d c}$

$i_{c, i}$

$i_{d c, i}$

$d_{i}$

$d_{i i}$

$d_{a v}$

$D_{i}$

$D_{i i}$

$d_{\text {max }, i}$

C

L

$R_{d s(o n)}$

$R_{L d c}$

$R_{L}$

$v_{s w}$

$Q_{\text {max }, i}$

$\mathrm{SOC}_{0, i}$

$S O C_{i}$

$O C V_{0, i}$

$O C V_{i}$

module

Steady state current of $i^{\text {th }}$ battery module Instantaneous capacitor voltage of $i^{\text {th }}$ module

Steady state module dc-link voltage of $i^{\text {th }}$ module

Instantaneous capacitor voltage reference of $i^{\text {th }}$ module

Steady state total DC-link capacitor voltage

Instantaneous inverter dc-link capacitor voltage

Instantaneous total DC-link capacitor voltage reference

Steady state DC-link current

Instantaneous common DC-link current

Instantaneous capacitor current of the $i^{\text {th }}$ converter module Instantaneous DC-link current of the $i^{\text {th }}$ converter module

Instantaneous duty cycle of $i^{\text {th }}$ boost converter module

Instantaneous duty cycle of $i^{\text {th }}$ buck

converter module

Instantaneous overall duty cycle of the multilevel buck converter

Average duty cycle of $i^{\text {th }}$ boost converter module

Average duty cycle of $i^{\text {th }}$ buck converter module

Maximum duty cycle of $i^{\text {th }}$ converter module

Module dc-link capacitance

Module boost inductance

On-state resistance of the semi-conductor devices per module

Leakage resistance of the dc-link inductor Leakage resistance of the module boost inductor

Maximum switch voltage rating of a dcdc module

Maximum charge (capacity) of $i^{\text {th }}$ module Initial state-of-charge of $i^{\text {th }}$ battery

A

V

V

V

V

V

V

A

A

A

A module

Instantaneous state-of-charge of $i^{\text {th }}$ battery module

Initial open circuit voltage of $i^{\text {th }}$ module Instantaneous open circuit voltage of $i^{\text {th }}$ module
F

$\mathrm{H}$

$\Omega$

$\Omega$

$\Omega$

V

C p.u.

p.u.

$\mathrm{V}$

V 


\section{INTRODUCTION}

$\mathrm{T}$ here are significant interests in industry (e.g. ABB with GM, Sumitomo Corporation with Nissan) [1] - [2] and academia in re-using ex-transportation batteries in the grid system as a cost-effective alternative to existing off-the-shelf battery energy storage systems (BESS) [3] - [5]. Reference [1] discusses about the possibility of using electric car (batteries inside the car) as a domestic energy storage system and [2] discusses about the possibility of cost-reduction using second life batteries. A recent study [6] has reported that there will be a substantial supply of these second life batteries as the number of electric/hybrid vehicle grows from 2020's. The supply of these batteries could be from different sources, e.g. the same manufacturer but different vehicles (Electric cars/Bus or motorbike) or different manufacturers. As a result, second life batteries could have different nominal voltages $(12 \mathrm{~V}, 48 \mathrm{~V}$ or $200 \mathrm{~V}$ etc.) and capacities $(1 \mathrm{kWh}-100 \mathrm{kWh})$ depending on vehicles even if they are of the same chemistry.

The likely recycling route for ex-transportation batteries is that the vehicles will be returned to the manufacturer and they will supply the batteries directly or pass the batteries through contracts to a battery re-cycler. The battery will be stripped down into sub-modules and be tested before being leased or sold on for a second life application. It is impractical to strip the batteries down to cell level, however, within a vehicle there are likely to be modularized units which the battery can easily be reduced into. These sub modules will be minimally tested and sorted at the recycler or manufacturer before being sent on for a second life application.

In order to address challenges in integrating these second life batteries to the grid system modular power electronic converters are preferred [7] - [9] because this type of converters provides a better reliability and flexibility compared to traditional two level designs. Previous research on modular BESS considered the same type of batteries and focused mainly on high power, medium voltage grid systems (e.g. $>100 \mathrm{~kW}$ around $3.3 \mathrm{kV} / 6.6 \mathrm{kV}$ ) [10] - [13]. The reason modular topology research studies have concentrated in large scale installations is the lack of availability of the high voltage, high frequency, efficient semi-conductor devices. Increased attention was paid in developing state-of-charge (SOC) balance control within the modular converter using equal module size [13] - [15]. This type of balancing control is justifiable when the same type of sources with similar characteristics is present. Predominantly cascaded multilevel converter (CMC) and modular multilevel converters (MMC) are used in those studies. Some of the recent studies have used hybrid cascaded converters using the same type of battery system such as described in [16]. The multilevel dclink voltage with an output H-bridge module was used. All these types of converters are pre-dominantly buck type and demand the overall dc-side voltage is higher than the ac-side voltage for suitable power transfer. However, they cannot be used for low voltage batteries unless a very high number of modules is employed which increases the cost and control complexity.

On the other hand, previous research studies on energy storage systems (ESS) or hybrid energy storage system (HESS) e.g. battery with super-capacitors [17] - [18], battery with PV/wind or fuel cells [19] - [21] have pre-dominantly used a single battery bank with a dc-dc boost converter, multiport dc-dc converter [22] or sometimes directly in parallel to the inverter dc-link [23]. The primary focus of these research studies was in developing grid-side energy management strategies. There are some applications which use dual inverter based schemes, e.g. [24] where the energy storage element was directly integrated across the dc-link. Moreover, parallel multilevel dc-link converters were also employed for the integration of battery and super-capacitor cells together as shown in [25] similar to [16]. The principle concept was based on multilevel dc-link voltage with H-bridge module at the grid side without the bulky dc-link capacitor. However, the major drawback of this multilevel dc-link topology are: a) the lack of centralized dc-link which is often desired for energy storage or micro-grid applications to supply dc-loads and other dc energy sources, b) demands high number of cells or energy storage elements just to meet the voltage levels and c) four high voltage semiconductors are required at the grid side depending on the total dc-side voltage. These research studies can be categorized in two groups: a) boost type where a low voltage $(<400 \mathrm{~V})$ battery bank is used and $b)$ a buck type where a high voltage battery $(>600 \mathrm{~V})$ is available. There are only a few recent research studies which have considered multiple battery types within an energy storage system to optimize the system cost and volume as shown in [26] - [28]. However, they do not focus on the converter side or power electronic design challenges in integrating hybrid batteries together.

Integration of widely different battery types within a grid-tie converter has not been explored much in the literature. This is perceived to be an important challenge in second life battery applications because the battery availability especially at early stages depends very much on the supply chain feed through where a boost or buck type modular converter on its own may not be sufficient. Moreover, the presence of hybrid batteries within an ESS provides the opportunity to optimize the system and also provides additional flexibilities. To address this, a generalised boost-buck type of dc-side modular converter using different battery modules was described in [29] as shown in Fig. 1. Within ref [29], the operation of a new boost-buck mode with its associated control structure for hybrid battery integration was described and an experimental study showing feasibility was undertaken under a couple of different operating conditions.

However, no detailed description of other operating modes and practical considerations around switching performance and efficiency although alluded to were not quantified or compared. Different operational modes have different characteristics for example; operational envelope, voltage and current ripple on each module, power losses/efficiency and control ranges. This influences the reliability as well as the overall performance of the system. This paper aims to expand upon this work to quantify and compare these key characteristics to establish a universal dc-side modular converter topology.

Therefore, the paper contributes in following areas:

a) Quantifying switching performances of all the converter modes of operation by deriving the expressions of voltage ripple, current ripple in the module inductor and capacitor and comparing these to measured values where practical; 


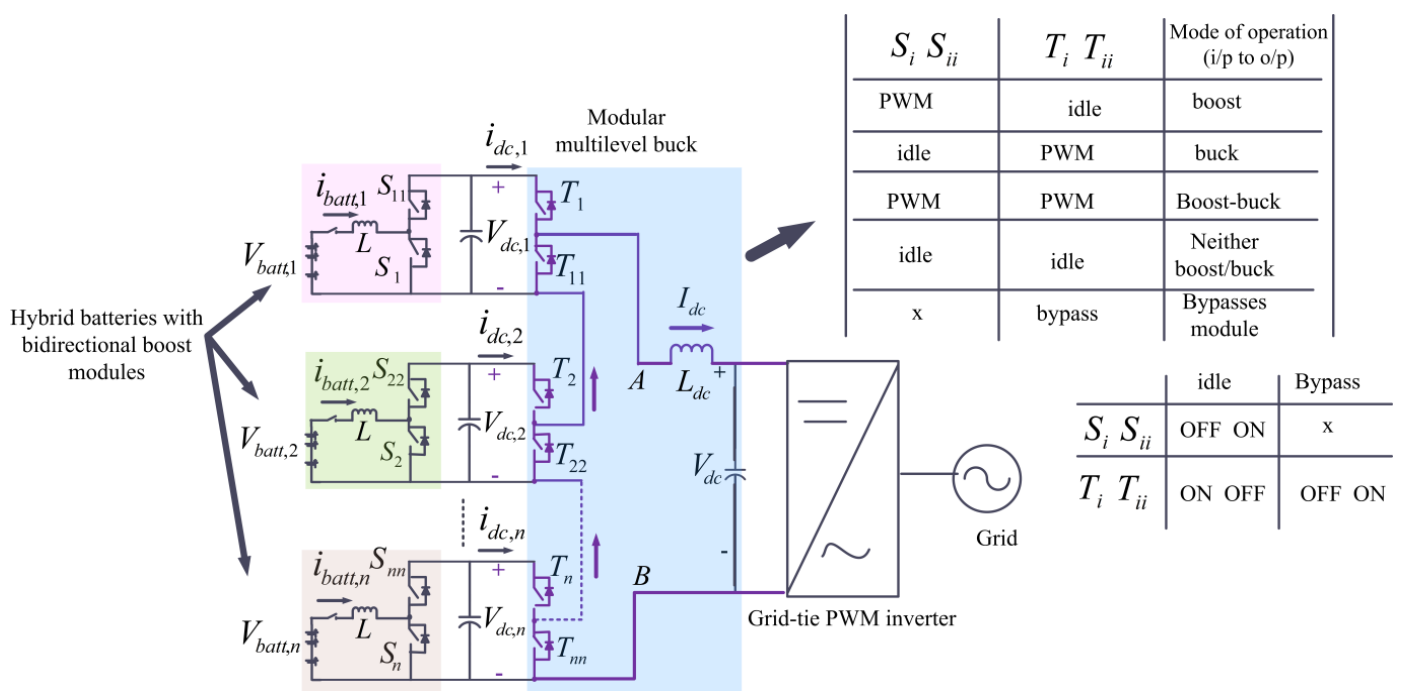

Fig. 1 Modular boost-multilevel buck topology for hybrid battery application and its switching combination

b) Comparing the converter control ranges, control method and inherent design complexity;

c) Quantifying the efficiency of the converter under different operational modes and comparing these to measured values where practical;

Finally, the analytical studies have been validated using a scale-down multi-modular hybrid battery energy storage system prototype by running in different modes under grid connected conditions.

\section{MODULAR CONVERTER TOPOLOGY AND ITS DIFFERENT MODES}

A Modular converter system is recommended for this application in [7] - [8] from a reliability and cost point of view. A suitable topology was proposed in [29]. Three operational modes are possible in the converter shown in Fig. 1. It can be seen that the converter is capable of integrating a wide range of battery voltages. These operational modes are: a) boost mode where module switches $S_{i}, S_{i i}$ operates in PWM mode while $T_{i}$ is kept $\mathrm{ON}$ and $T_{i i}$ is OFF $\forall i=1 \ldots \mathrm{n}$ similar to [30] - [32], b) buck mode where $T_{i}, T_{i i}$ operates in PWM while $S_{i}$ is kept OFF and $S_{i i}$ is ON $\forall i=1 \ldots \mathrm{n}$ similar to [33] and c) boost- buck mode where $S_{i}, S_{i i}$ and $T_{i}, T_{i i}$ can all operate in PWM mode, $\forall i=1 \ldots$ n or some of the $S_{j}, S_{j j}$ operates in idle mode $\forall i \neq j$ depending on set of batteries which offers an additional flexibility.

In this application of hybrid batteries where batteries of different types are integrated together within a single converter, each module within the modular converter consists of different battery types with different voltage and maximum charge capacity. Therefore, a module balancing strategy is not directly applicable in the current context. Each battery module should be dealt independently according to their characteristics. This implies a distributed control or a power sharing strategy. Due to this strategy, each mode has different current ripple and voltage ripple in its module inductor and capacitors. These current ripples and voltage ripples are important design criterion for the converter design which also influences the performance, efficiency and reliability of each converter module. For example, the inductor current ripple indicates the peak current stress the semiconductors will be subjected to and the current ripple in the capacitor influences its lifespan because a high current ripple can cause high losses in the ESR inside the capacitor which increases internal temperature and thereby reducing the reliability as reported in [34].

\section{A. Boost Mode}

Fig. 2(a) shows the boost of operation of the converter. This is similar to the one described in photovoltaic application [30] - [32] with a major difference being that this is bidirectional rather a unidirectional converter. Moreover, it has the capability to bypass the faulty battery module during the boost operation using $T_{i}, T_{i i} \forall i=1 \ldots n$ as indicated in Fig. 1. All the module output capacitors are connected in series to form the central dc-link voltage of the inverter. This mode is possible only when low voltage batteries and/or low number of modules are present such that sum of all module voltages meets the condition $\sum v_{b a t t, i}<v_{d c}$. The main equations of the converter are given in (1) - (3) where $d_{i}$ is the duty ratio of the switch $S_{i}$ and the main control variable which controls the power flow. The quantities like $L, R_{L}$ and $C$ are the module inductor, its leakage resistance and module dc-link capacitor respectively.

$$
\begin{aligned}
& L \frac{\mathbf{d} i_{b a t t, i}}{\mathbf{d} t}+R_{L} i_{b a t t, i}+\left(1-d_{i}\right) v_{d c, i}=v_{b a t t, i} \forall i=1 \ldots n \\
& C \frac{\mathbf{d} v_{d c, i}}{\mathbf{d} t}-\left(1-d_{i}\right) i_{b a t t, i}=-i_{d c} \forall i=1 \ldots n \\
& v_{d c}=v_{d c, 1}+v_{d c, 2}+\cdots v_{d c, n}
\end{aligned}
$$

Due to the idle operation of the buck side $\left(T_{i}\right.$ is $\mathrm{ON}$ and $T_{i i}$ OFF) each boost converter module effectively sees a constant load current $I_{d c}$ across the module capacitor $C$. Fig. 3 presents the switching performance in the boost mode showing how switching signals are generated along with the inductor current, the capacitor current and the capacitor voltage. Expressions of inductor current and capacitor voltage ripples are given in (4) $-(5)$. 
Low no. of modules/low voltage batteries
High no. of modules/ high voltage batteries

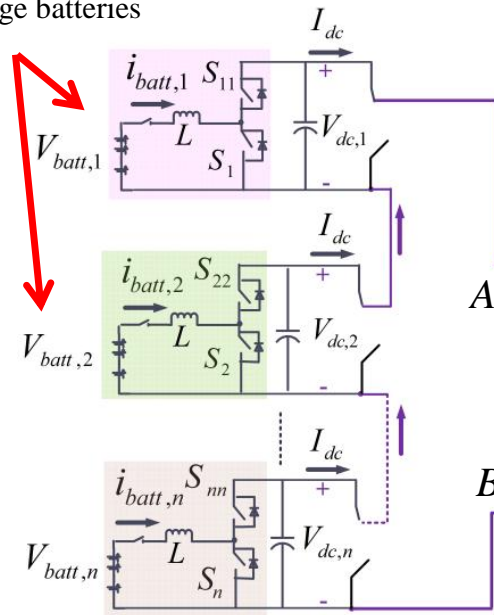

(a)
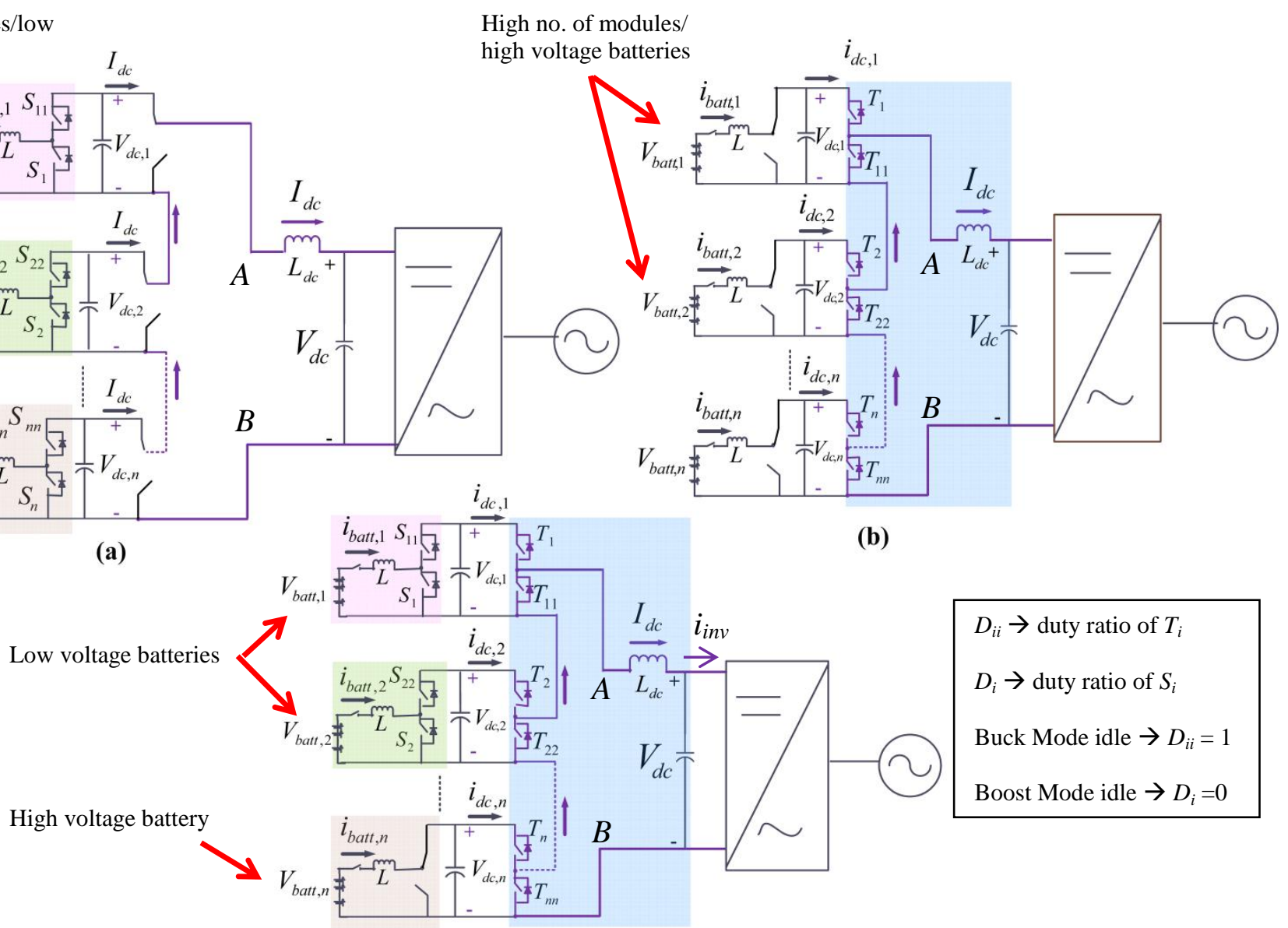
$D_{i i} \rightarrow$ duty ratio of $T_{i}$
$D_{i} \rightarrow$ duty ratio of $S_{i}$
Buck Mode idle $\rightarrow D_{i i}=1$
Boost Mode idle $\rightarrow D_{i}=0$

(c)

Fig. 2 Operational modes of the Boost-multilevel buck converter: a) boost mode, b) modular multilevel buck mode, c) boost- buck mode

It can be seen that the capacitor current is dependent on $i_{d c}$ and $i_{\text {batt }, i}$. The rms current ripple is derived in (8) through the capacitor current $\left(i_{c, i}\right)$ waveform of Fig. 3 . Note it is only dependent on $D_{i}$ because $D_{i i}$ is set equal to 1 in this mode as shown in Fig. 2(a).

$\Delta i_{\text {batt }, i}=\frac{V_{\text {batt }, i}}{L} D_{i} T_{s}=\frac{\left(1-D_{i}\right) D_{i}}{L} V_{d c, i} T_{s}$

$i_{c, i}=i_{b a t t, i}-I_{d c}$ and $\Delta V_{d c, i}=\frac{I_{d c}}{c} D_{i} T_{s}$

Using the information from Fig. 3

$i_{c, i}=-I_{d c}$ for $0 \leq t \leq D_{i} T_{s}$

$i_{c, i}=\left(I_{b a t t, i}+\frac{\Delta i_{\text {batt }, i}}{2}-I_{d c}\right)+\frac{\left(I_{\text {batt }, i}+\frac{\Delta i_{\text {batt }, i}}{2}-I_{d c}\right)}{\left(1-D_{i}\right) T_{s}}(t-$

$\left.D_{i} T_{s}\right)$ for $D_{i} T_{s} \leq t \leq T_{s}$

$I_{c, i(r m s)}=\sqrt{\frac{1}{T_{s}}\left(\int_{0}^{D_{i} T_{s}} i_{c, i}^{2} d t+\int_{D_{i} T_{S}}^{T_{S}} i_{c, i}{ }^{2} d t\right)}$ Rearranging,

$I_{c, i(r m s)}=\sqrt{\left(\left(1-D_{i}\right)\left(1+\frac{1}{3}\left(\frac{\Delta i_{b a t t, i}}{2}\right)^{2}\right) I_{b a t t, i}^{2}{ }_{b a t t, i}+D_{i} I_{d c}^{2}\right)}$
$L \frac{d i_{\text {bat }, i}}{d t}+v_{d c, i}=v_{\text {batt }, i} \forall i=1 \ldots n$

$C \frac{d V_{d c, i}}{d t}=i_{b a t t, i}-i_{d c, i} \forall i=1 \ldots n$

$L_{d c} \frac{d i_{d c}}{d t}+v_{d c}=d_{a v} \sum V_{d c, i}$ where $d_{a v}=\frac{\sum v_{d c, i} d_{i i}}{\sum v_{d c, i}}$

$C_{d c} \frac{d V_{d c}}{d t}=i_{d c}-i_{i n v}$ 
There could be two types of PWM methods in this mode: a) a phase shifted multiple carrier PWM method where the same control signal is used as reported in [33] and b) uniform carrier method where the control signals are different as described in [29]. Both generate a multilevel voltage across the dc-link inductance $\left(L_{d c}\right)$ as shown in Fig. 4. As a result of this, it reduces the inductor current ripple. However, in the context of hybrid batteries, a previous research study [29] showed that the uniform carrier PWM method is more applicable as it provides the opportunity to utilise each battery module independently according their characteristics using $d_{i i} \forall i=1 \ldots$ n.

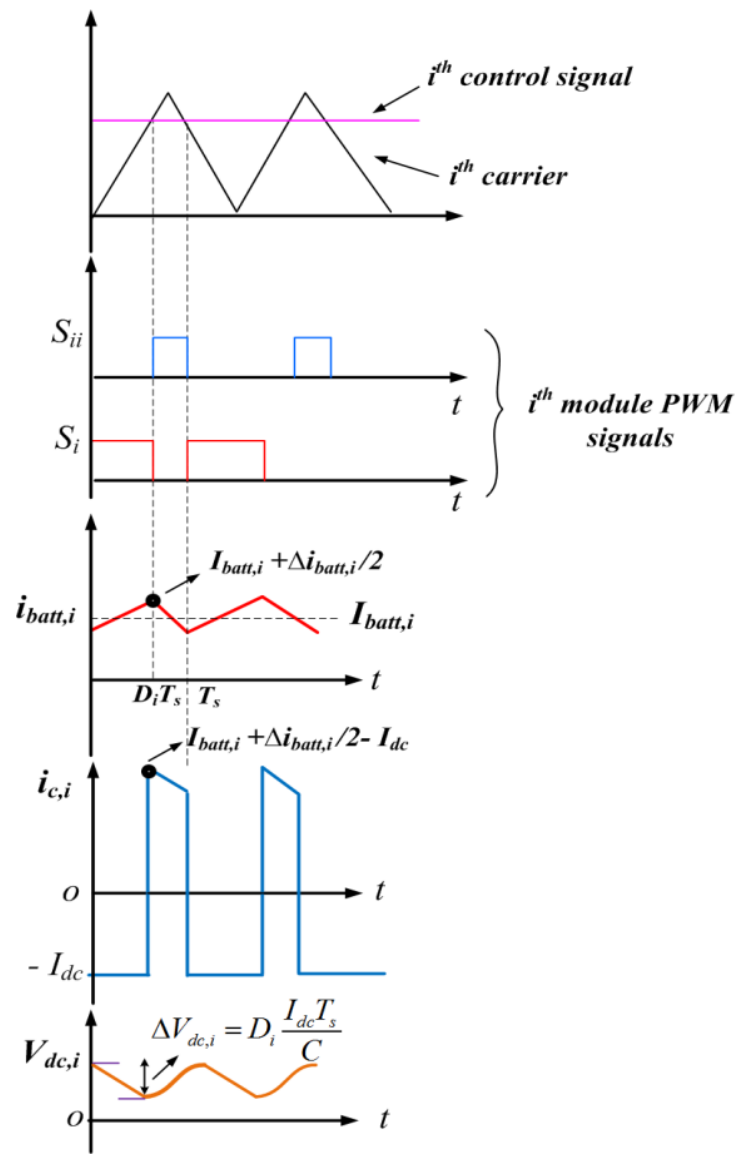

Fig. 3 Switching performance in boost mode during discharging: current and voltage ripple

The switching operation of this mode is described in Fig. 4. Due to PWM operation of $T_{i}, T_{i i}$ each module sees a pulsating load current $\left(i_{d c, i}\right)$ unlike a constant load current in the boost mode. Moreover, due presence of non-uniform battery module voltages the steps in the multilevel voltage waveform could be uneven as shown in Fig. 4. Therefore, the capacitor ripple will be different in this operating mode. The inductor sees negligible ripple current in this case because the switch $S_{i i}$ is always $\mathrm{ON}$ and the ripple in $i_{d c, i}$ goes directly into the capacitor. Note that the shape of capacitor current will be different in charging and discharging because $i_{c, i}=i_{b a t t, i}-$ $i_{d c, i}$ during discharging and $i_{c, i}=i_{d c, i}-i_{b a t t, i}$ during charging condition. The discharging condition has been shown in Fig. 4. The expressions of capacitor current and the voltage ripple are derived in (13). The expression of rms current ripple can be found in (17) similar to (8). Note the rms capacitor current is only dependent on $D_{i i}$ unlike in the boost mode.
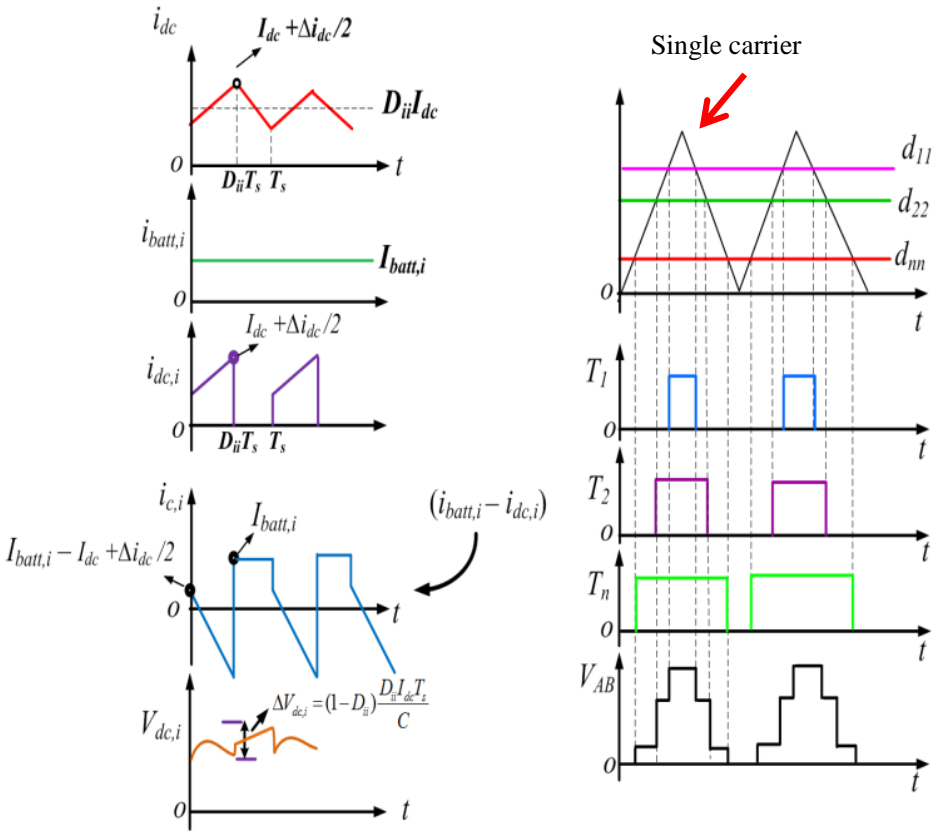

Fig. 4 Switching performance of multilevel buck mode during discharging: uniform carrier PWM

$$
\begin{aligned}
& i_{c, i}=I_{b a t t, i}-i_{d c, i} \text { and } \Delta V_{d c, i}=\left(1-D_{i i}\right) \frac{D_{i i} I d c}{C} T_{s} \\
& i_{c, i}=\left(I_{b a t t, i}\right)+\frac{\left(I_{d c}+\frac{\Delta i_{d c, i}}{2}-I_{b a t t, i}\right)}{\left(1-D_{i i}\right) T_{s}}\left(t-D_{i i} T_{s}\right) \text { for } 0 \leq t \leq \\
& D_{i i} T_{s} \\
& i_{c, i}=-I_{b a t t, i} \text { for } D_{i i} T_{s} \leq t \leq T_{s} \\
& I_{c, i(r m s)}=\sqrt{\frac{1}{T_{s}}\left(\int_{0}^{D_{i i} T_{s}} i_{c, i}{ }^{2} d t+\int_{D_{i i} T_{s}}^{T_{s}} i_{c, i}{ }^{2} d t\right)} \text { Or } \\
& I_{c, i(r m s)}=\sqrt{\left(I^{2}{ }_{b a t t, i}+D_{i i}\left(1+\frac{1}{3}\left(\frac{\frac{\Delta i_{d c}}{2} I_{d c}}{I_{d c}}\right) I^{2} d c\right)\right.}
\end{aligned}
$$

\section{Boost-Buck Mode}

In this case, either all the switches, $S_{i}, S_{i i}$ and $T_{i}, T_{i i}$ are operated in PWM mode or some of the switches $S_{j}, S_{j j}$ $(\forall i \neq j)$ are operated in idle mode $\left(S_{j}\right.$ is OFF, $S_{j j}$ is ON) depending on the set of batteries present as shown in Fig. 2(c). However, depending on the distribution of the duty $d_{i i}$ some module switches $T_{i}, T_{i i}$ may also operate in idle mode (when $d_{i i}=1$ ). This is mainly because the high voltage module may not need any boost operation from the input and a boost operation from the high voltage battery also incurs additional switching losses which reduces the system efficiency. This mode is valid in both situations, $\sum v_{b a t t, i}>v_{d c}$ or $\sum v_{b a t t, i}<$ $v_{d c}$. This implies that the boost-buck mode is capable of controlling any system with different battery types even if they have widely different voltage levels using a combination of all the module switches. Moreover, it can also bypass any faulty 
battery module and increase the energy flow through the other modules without changing the mode of operation until the faulty module can be replaced. This way it provides more flexibility and more versatility compared to the other modes. The dynamic equations are combinations of (1) - (3) and (9) (12) in this mode. The switching operation of the boost converter will be similar to Fig. 3 and the operation of the multilevel buck converter will be similar to Fig. 4. Due to PWM operation of all the four switches $\left(S_{i}, S_{i i}\right.$ and $\left.T_{i}, T_{i i}\right)$, both inductor ripple and capacitor current ripple are important in this mode. The expression of inductor current ripple will be the same as (4) but the capacitor current is more complicated to derive because the duty ratios and also switching frequencies of $S_{i}$, and $T_{i}$ can be independent of each other could be totally independent of each other. Therefore, an example inductor, capacitor current ripple is shown in Fig. 5 assuming $i_{d c}$ and $i_{\text {batt } i}$ are independent. The switching frequency has been assumed to be the same for $S_{i}$, and $T_{i}$ for simplicity but they can be different. The ripple content of the module inductor current $i_{\text {batt, } i}$ and the dc-link current $i_{d c, i}$ is absorbed by the module capacitor. Therefore, It is interesting to note that the positive current peak is dependent on $i_{\text {bat }, i}$ while the negative current peak is dependent on $i_{d c}$ which means that the positive peak of the module capacitor current is greater than the negative current peak as $i_{b a t t, i}>i_{d c}$ for the boost operation. The exact nature of capacitor current $\left(i_{c, i}\right)$ and capacitor voltage ripple is dependent on relative values of $D_{i}$ and $D_{i i}$ and also synchronisation between $i_{d c}$ and $i_{b a t t, i}$.

Two cases are studied: a) when the duty ratio of $S_{i}$ is greater than the duty ratio of $T_{i}$ (i.e. $D_{i i}<D_{i}$ ), b) duty ratio of $S_{i}$ is less than the duty ratio of $T_{i}$ (i.e. $D_{i i}>D_{i}$ ). The waveform of the capacitor current in this mode waveform is shown in Fig. 5. It is clear that the ripple current is dependent on both $D_{i i}$ and $D_{i}$ as expected. The rms value of the capacitor current is derived in (18) by following the similar method described for the boost and buck mode.

$I_{c, i(r m s)}=\sqrt{\left(\left(1-D_{i}\right)\left(1+\frac{1}{3}\left(\frac{\Delta i_{\text {batt }, i}}{I_{\text {bat }, i}}\right)^{2}\right) I^{2}{ }_{\text {batt }, i}+D_{i i} I^{2} d c\right)}$

Fig. 6 shows the variation of RMS capacitor current ripple in 3D plane in two stages: a) a general variation of duty ratios $\left(D_{i}\right.$ and $D_{i i}$ ) between $0-1$ and b) a specific variation of duty ratios within a certain charge/discharge cycle for two modes of operations: boost and boost-buck mode using expressions (8) and (18). It can be seen from Fig. 6(a), the surface plot of the boost mode remains zero for all $D_{i i}$ 's except unity because the top switch $T_{i}$ is always on in this mode. The surface plot is mostly concentrated around $D_{i i}=1$ which clearly implies that capacitor current ripple is independent of $D_{i i}$. On the other hand, the boost-buck mode produces higher current ripple for most of the regions within the plane.

However, the duty ratios $D_{i}$ and $D_{i i}$ both do not vary between 0 and 1 simultaneously within a certain charge/discharge cycle. Therefore, a specific comparison is shown in Fig. 6(b) where the duty ratio $D_{i}$ of a module varies between $0.6-0.75$ for the boost mode and $D_{i i}$ varies between $0.7-1$ for the boost-buck mode within a specific discharging cycle. Note: the surface of the boost mode lies slightly higher than the boost-buck mode for higher values of $D_{i i}$ which means the boost mode produces a higher current ripple compared to the boost-buck mode at this range but the boostbuck mode produces higher ripple at lower values of $D_{i i}$. Therefore, it can be concluded that the capacitor current ripple depends on relative values of $D_{i}$ and $D_{i i}$.

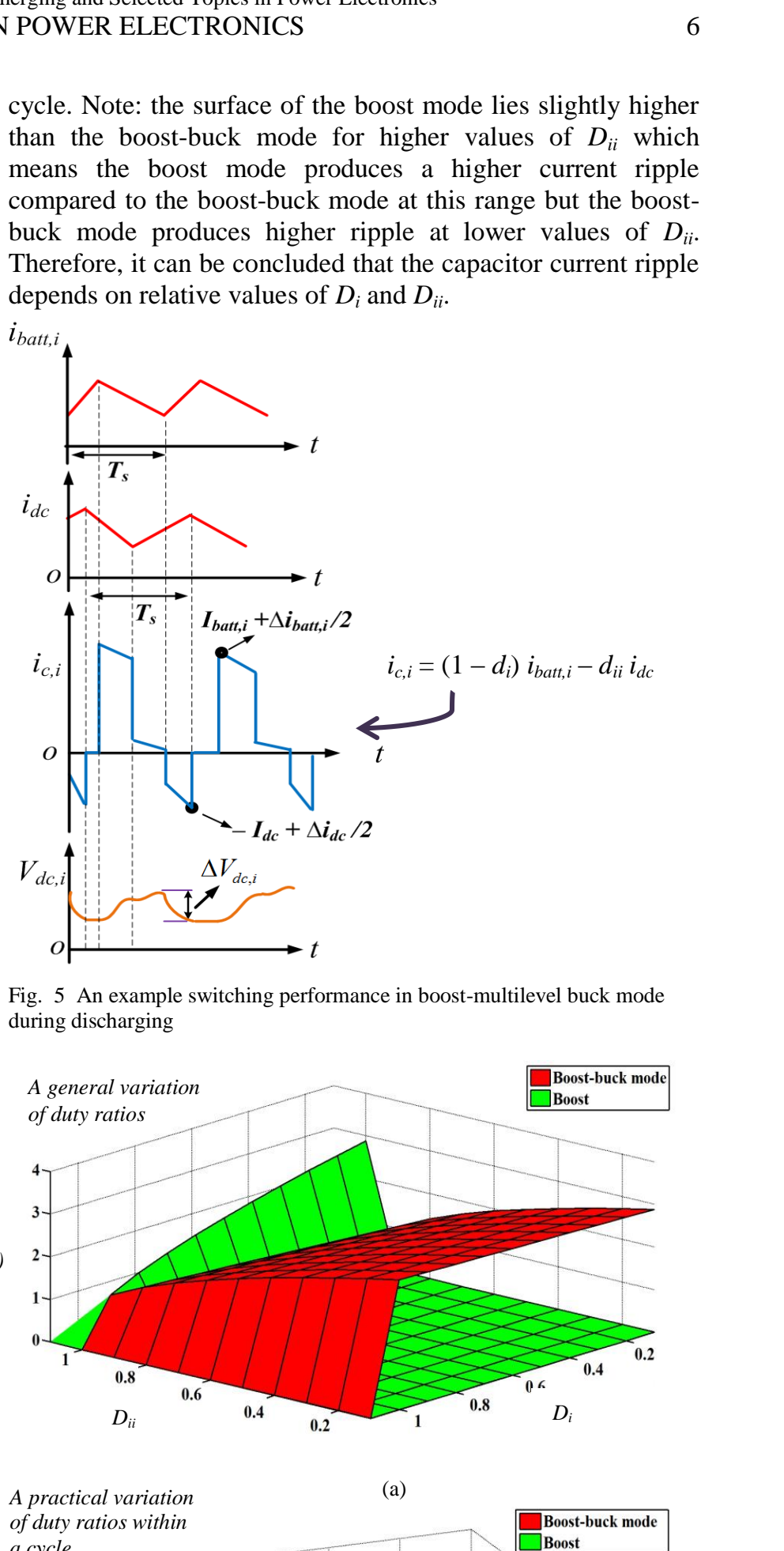

Fig. 5 An example switching performance in boost-multilevel buck mode during discharging

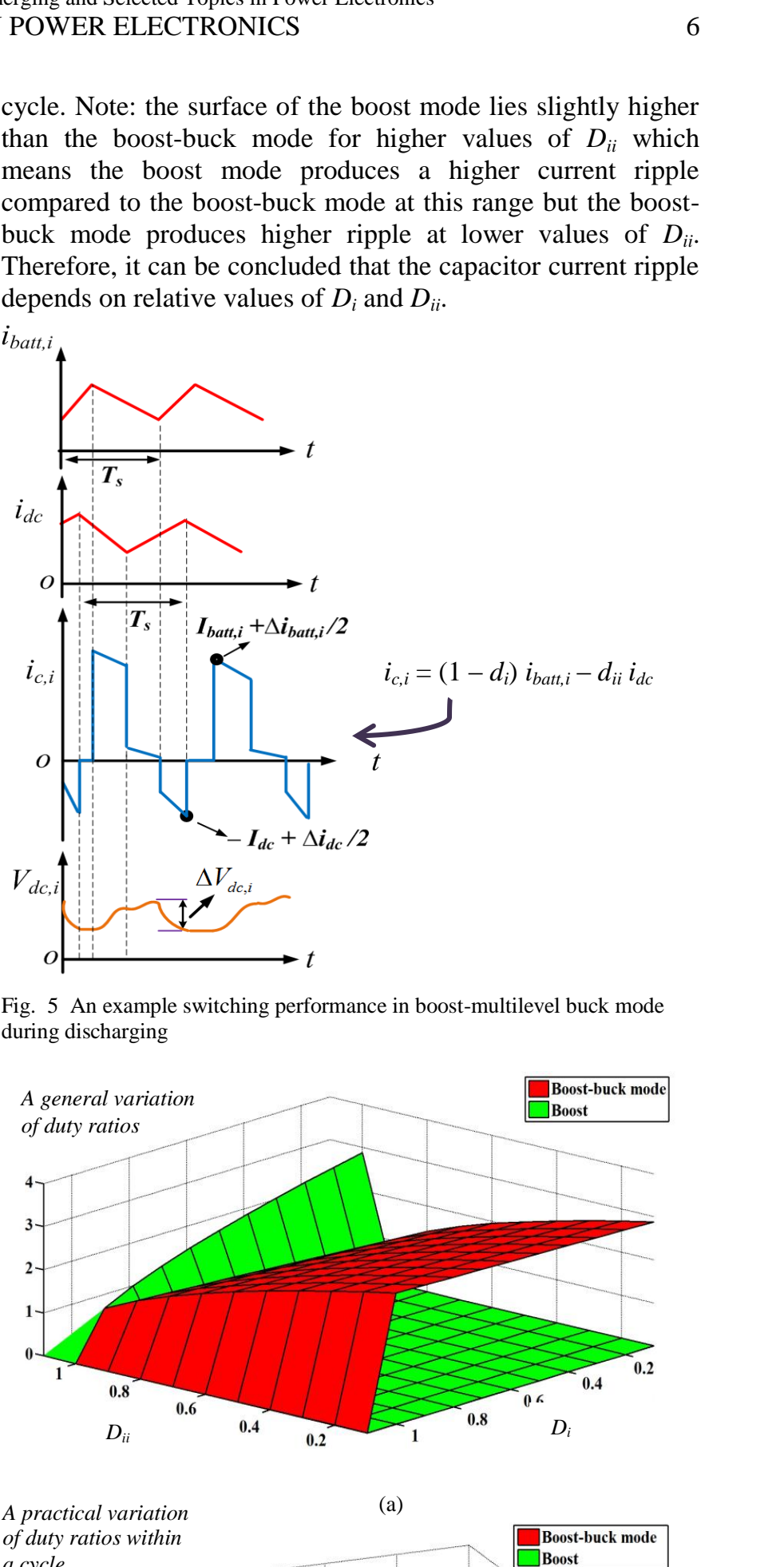

A practical variation

(a) of duty ratios within a cycle $I_{c, i}$ (A)

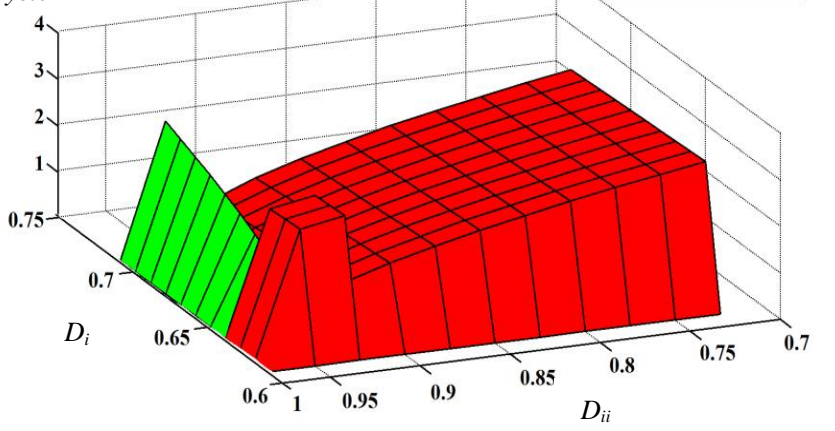

(b)

Fig. 6 RMS capacitor current: a) general comparison, b) specific comparison 


\section{HYBRID BATTERIES AND ANALYTICAL COMPARISON OF DIFFERENT MODES}

There could be a hybrid mix of battery modules with different voltage levels and maximum capacity within the SLBESS. Therefore each of these module types will charge/discharge at different rates and have different maximum/minimum safe amounts of charge and voltages. The strategy adopted in this paper is therefore to ensure that the charging/discharging trajectory of the modules during a charging or discharging cycle will all arrive at their maximum and minimum values at the same time as shown in Fig. 7 [9], [29]. Charging/discharging depends purely on the module current $\left(i_{\text {batt }, i}\right)$. Therefore a current sharing has been followed based on weighting factors as shown in (19).

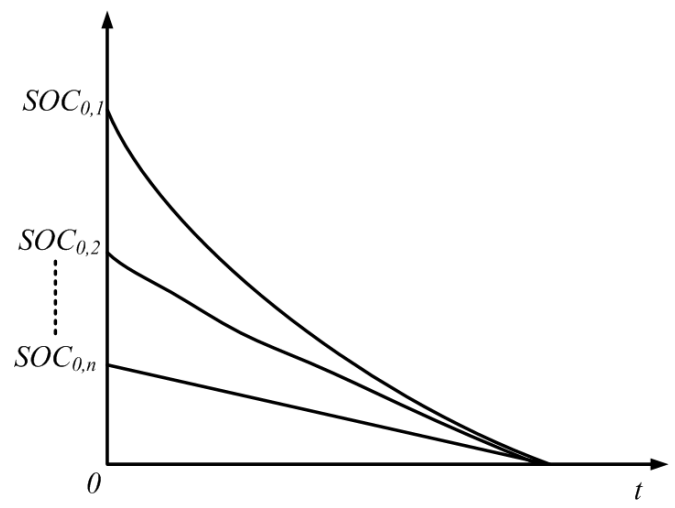

Fig. 7 Hybrid battery discharge trajectory

Different operational modes described in Fig. 2 and section II have different application range depending on the set of batteries and different switching strategies gives rise to wide flexibility as well as different power losses. In order to perform a comparison among the modes, a set of hybrid batteries was chosen as shown in Table 1 based on the laboratory set-up. Battery capacities are chosen to be widely different (almost in 1:10 ratio) and also battery voltages vary between $7.2 \mathrm{~V}$ and $24 \mathrm{~V}$.

$\frac{i_{\text {batt }, 1}}{\omega_{1}}=\frac{i_{\text {batt }, 2}}{\omega_{2}}=\cdots=\frac{i_{\text {batt }, n}}{\omega_{n}}, \omega_{i}=f\left(V_{b a t t, i}, S O C_{i}, Q_{\max , i}\right)$

$\omega_{i}=\frac{\operatorname{SOC}_{i} Q_{\max , i}}{\sum_{k=1}^{n} v_{\text {batt }, k} \operatorname{SOC}_{k} Q_{\max , k}}$ for discharging, $=$

$\frac{\left(1-S O C_{i}\right) Q_{\max , i}}{\sum_{k=1}^{n} v_{\text {batt }, k}\left(1-S O C_{k}\right) Q_{\max , k}}$ for charging And $\sum_{i=1}^{n} \omega_{i}=1$

\section{A. Range of Operation/Operational Envelope}

It is clear from (19) that the relative weighting factor $\left(\omega_{i}: \omega_{j}\right)$ or current distribution ratio can be widely different within a set of batteries depending on their initial SOC and capacity $\left(Q_{\max }\right)$. This may demand significantly different current levels (high values of $i_{\text {batt }, i}: i_{\text {batt }, j}$ ) within the modular converter to control the hybrid battery modules according to Fig. 7. Therefore, it is necessary to derive this range. Module power balance equations can be used to derive how widely the module current could be controlled.

\section{Table 1 HYBRID BATTERIES UNDER CONSIDERATION}

\begin{tabular}{|l|l|}
\hline $\begin{array}{l}\text { Battery module }-1 \\
\text { (lead acid) }\end{array}$ & $12 \mathrm{~V}, 10 \mathrm{Ah}-V_{\max }=14 \mathrm{~V} V_{\min }=9.5 \mathrm{~V}, \mathrm{Z}_{\mathrm{nom}}=$ \\
\hline $\begin{array}{l}\text { Battery module }-2 \\
\text { (lithium Titanate) }\end{array}$ & $24 \mathrm{~V}, 60 \mathrm{Ah}-V_{\max }=27 \mathrm{~V} V_{\min }=18 \mathrm{~V}, \mathrm{Z}_{\mathrm{nom}}-$ \\
\hline $\begin{array}{l}\text { Battery module }-3 \\
(\text { NiMH) }\end{array}$ & $7.2 \mathrm{~V}, 6.5 \mathrm{Ah}, V_{\max }=8.5 \mathrm{~V}, V_{\min }=5 \mathrm{~V}, \mathrm{Z}_{\mathrm{nom}}=$ \\
\hline $\begin{array}{l}\text { Battery module }-4 \\
\text { (lead acid) }\end{array}$ & $0.015 \Omega$ \\
\hline
\end{tabular}

Boost Mode (Mode - 1): The first mode (Fig. 2(a)) is applicable only when $\sum v_{b a t t, i}<v_{d c}$ and also the lower limit of $i_{\text {batt, } i}$ is limited by the common dc-link current $i_{d c}$ to satisfy the constraint of a boost converter while the upper limit of $i_{\text {batt }, i}$ is restricted by the maximum switch stress $\left(v_{s w}\right)$ of a module and the common dc-link current $i_{d c}$ as shown in (20) and (21). The $i_{d c}$ is decided by the power level of the grid-tie converter. In the case where this limit exceeds the maximum discharge current of a battery module, the current level of the module needs to be limited accordingly. This is shown in Fig. 8 (a) where the operating zone for the boost mode is described.

Power balance equation in the boost mode per module,

$v_{d c, i} i_{d c}=v_{\text {batt }, i} i_{\text {batt }, i} \quad$ Where $\quad i_{\text {batt }, i} \geq i_{d c} \leftarrow$ boost converter constraint

$i_{\text {batt }, i}=\frac{V_{d c, i}}{V_{b a t t, i}} i_{d c}$

Now using (20) and deploying the condition $v_{d c, i, \max }=v_{s w}$, the following can be written.

$i_{d c} \leq i_{\text {batt }, i} \leq \frac{v_{s w}}{v_{\text {batt }, i}} i_{d c}$

Buck Mode (Mode - 2): The second mode of operation (Fig. $2(\mathrm{~b}))$ is applicable when $\sum v_{b a t t, i}>v_{d c}$. The upper limit of $i_{\text {batt }, i}$ is limited by the common dc-link current $i_{d c}$ to satisfy the constraint of a buck converter while there is no lower limit in this mode as shown in (23). This is shown in Fig. 8(b) where the operating zone for the buck mode is presented.

Power balance equation in the buck mode per module,

$v_{d c, i} i_{d c, i}=v_{\text {batt }, i} i_{\text {batt }, i} \quad$ Where $\quad i_{\text {batt }, i} \leq i_{d c} \leftarrow$ buck converter constraint

$v_{b a t t, i}\left(d_{i i}\right) i_{d c}=v_{b a t t, i} i_{b a t t, i}$

$0 \leq i_{\text {batt }, i} \leq i_{d c}$ 


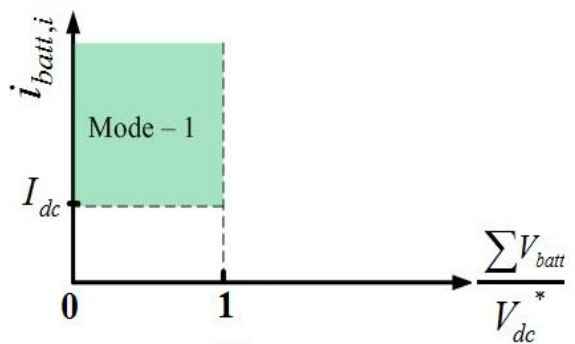

(a)

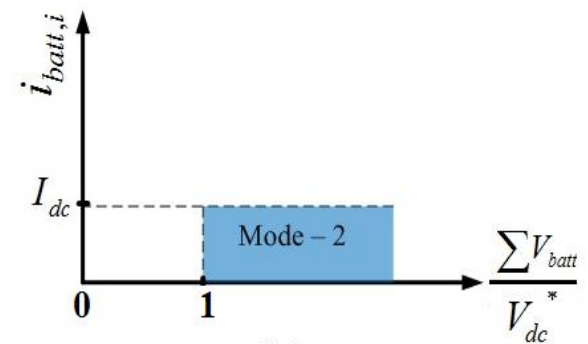

(b)

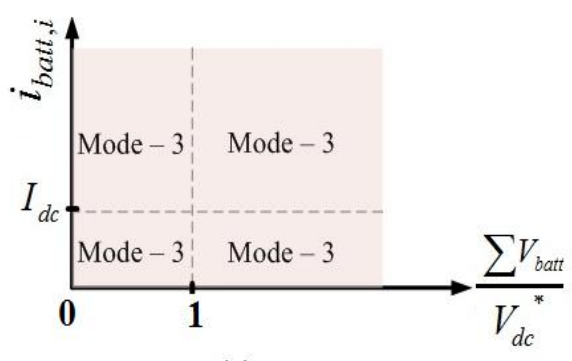

(c)

Fig. 8 Operational envelope or control range for three modes of the converter: a) mode 1: boost, b) mode 2: buck and c) mode 3: boost-buck

Boost-buck mode (Mode - 3): The third mode of operation (Fig. 2(c)) is applicable irrespective of the set of batteries and voltage levels. The upper limit of $i_{\text {batt, } i}$ is limited by the maximum boost ratio or switch rating $\left(v_{s w}\right)$ while there is no lower limit in this mode as shown in (24).

$v_{d c, i}\left(d_{i i}\right) i_{d c}=v_{b a t t, i} i_{b a t t, i} \rightarrow 0 \leq i_{b a t t, i} \leq \frac{v_{s w}}{v_{b a t t, i}} i_{d c}$

It can be observed from above expressions and from Fig. 8 that both boost and buck mode have a narrower control and application range compared to the boost-buck mode. Therefore, the boost-buck mode could offer a more general method of operation and a wider operating zone with the plane compared to other modes.

In order to show this limitation and differences between the modes, a set of simulation studies has been presented from Fig. 9 to Fig. 11. Simulation results have been presented in two stages: a) system level results ensuring the satisfactory grid connected operation of the converter in boost and boostbuck mode and b) current sharing results showing the major differences in the range of control operation between two modes of operation. Fig. 9 and Fig. 10 show the system level results in boost and boost-buck mode respectively showing the grid current and grid voltage together along with the dc-link voltage and dc-link currents. Note the converter is switched from charging to discharging mode at $\mathrm{t}=0.5 \mathrm{~s}$. The transition between two modes is shown. On the other hand Fig. 11 shows four dc-side currents at an instant when the grid-tie converter switches from charging to discharging mode. Fig. 11(a) shows a response using the boost mode and Fig. 11(b) depicts the similar response using the boost-buck mode.

Since a 60Ah battery module is integrated with $6.5 \mathrm{Ah}$ and 10Ah battery modules, the module -2 (60Ah battery) demands a higher share of current. However, in boost mode, module currents are limited by the common dc-link current $i_{d c}$ as shown in Fig. 11(a) where $i_{d c}$ has a $100 \mathrm{~Hz}$ component as the single phase system has a double frequency component (2x50) in the power along with the dc-component (Fig. 11(a)). As a result of this hybrid battery modules are not appropriately utilised. On the other hand, Fig. 11(b) shows that module currents are quite distinct compared to the boost mode. Therefore, the former mode is applicable when there is similar range of battery characteristics present while the latter mode is more applicable for widely different battery characteristics.
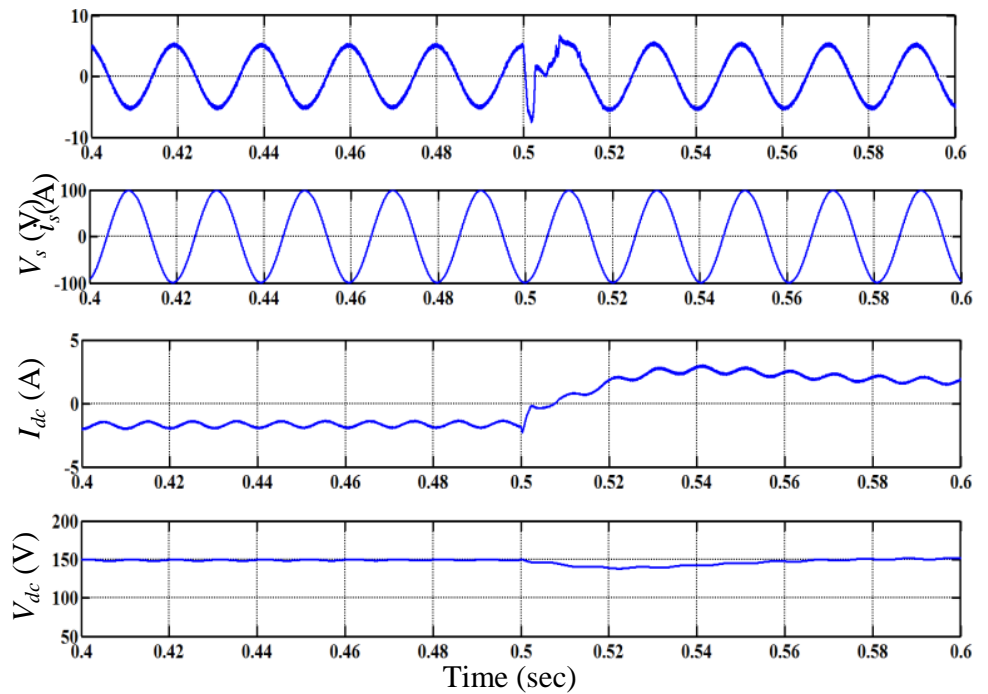

Fig. 9 Grid connected operation switching from charging to discharging mode: Boost mode
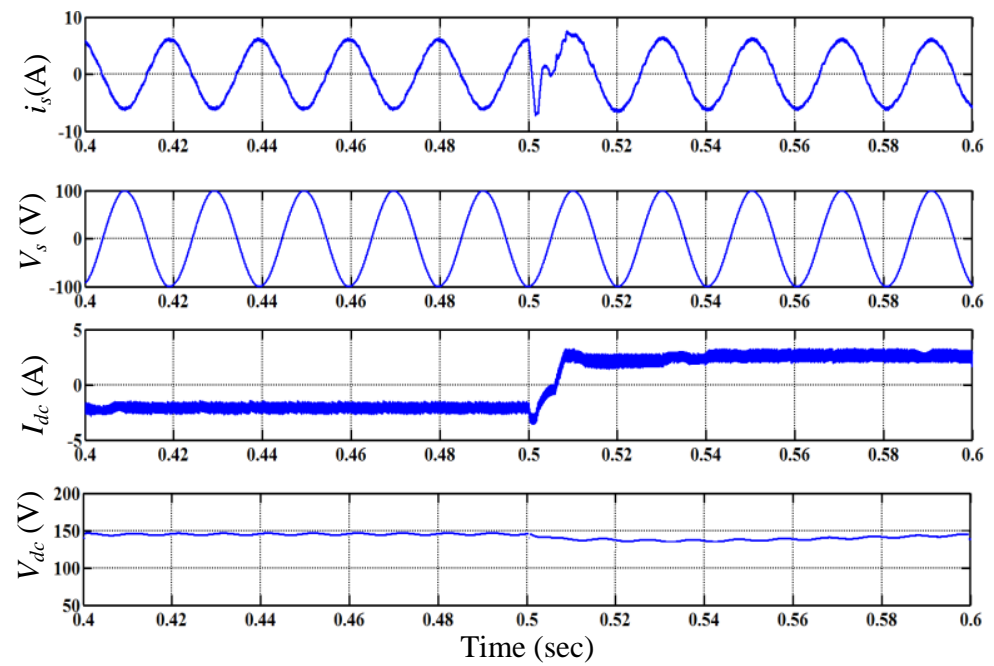

Fig. 10 Grid connected operation switching from charging to discharging mode: Boost-buck mode 

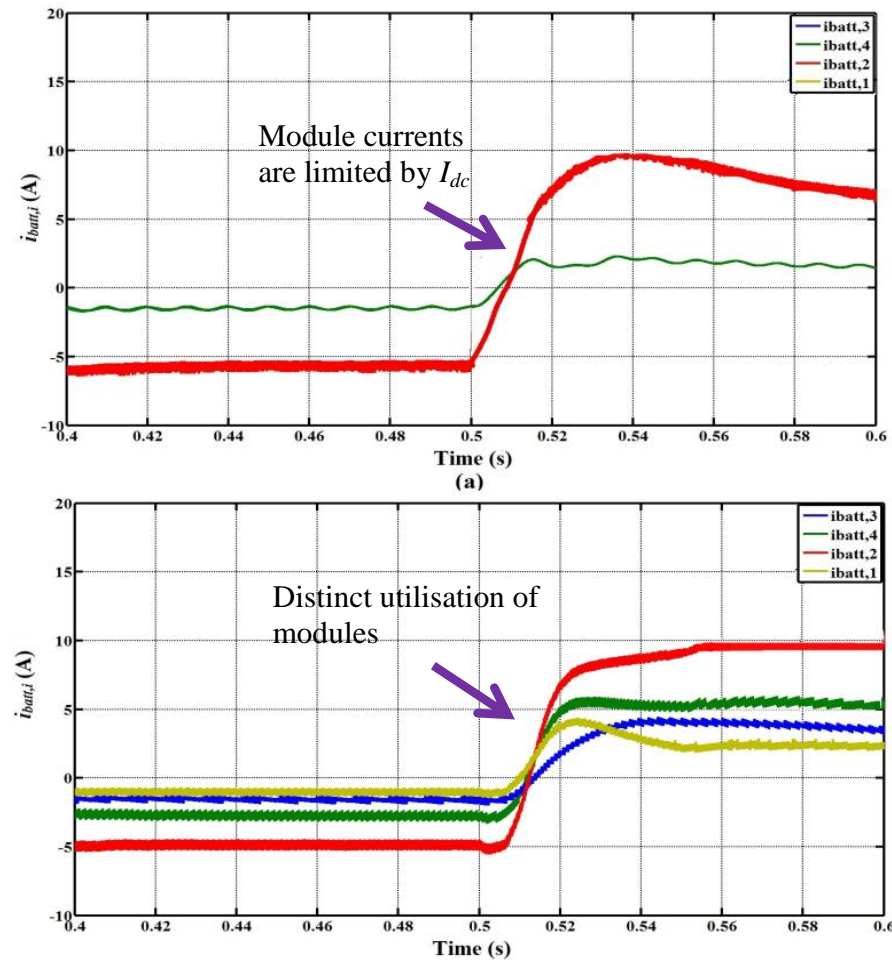

(b)

Fig. 11 Current sharing with widely different modules when converter switches from charging to discharging: a) in boost mode, and b) in boost-buck mode

\section{B. Control methods}

The main objective of the hybrid battery control scheme is to allow sharing the power among the different battery modules according to their weighting factor $\left(\omega_{i}\right)$ as described in (19) where $\omega_{i}$ is dependent on the module $S O C$ and capacity. In other words, it is essentially a current sharing strategy where the module current reference $\left(i_{b a t t, i}{ }^{*}\right)$ should be proportional to $\omega_{i}$. The grid side inverter operates on power control mode depending on the grid side requirement. Therefore, in order to make sure that the grid side converter works independent of the dc-side, it is necessary to maintain the central dc-link voltage constant on an instantaneous basis. The closed loop control schematic is shown in Fig. 12 for better understanding the control structure of the converter. The lines in red are the control signals. The control is performed per module basis based on estimated state-of-charge and available capacity as shown in Fig. 12. It can be seen from that each module is controlled according to its weighting function by measuring its voltage and current. The multilevel buck converter operates only in boost-buck and in the buck mode in which case, the duty ratio of each buck module $\left(T_{i}, T_{i i}\right)$ is generated from the estimated SOC and capacity. The line side inverter operates as a current source providing the necessary grid support.

Fig. 13 illustrates actual control loops for the boost, buck or boost-buck mode. The dc-side control structure is shown as the inverter control remains the same in all modes. Each mode requires module independent control which is achieved by different methods. For example, in boost mode, it is performed by distributing the total dc-link voltage of the inverter according to $\omega_{i}$ i.e. $v_{d c, i}=f\left(\omega_{i}\right)$ which implies $d_{i}=f$ $\left(\omega_{i}\right)$ whereas in buck or boost-buck mode, it is solely done using the duty ratio $d_{i i}$ i.e. $d_{i i}=f\left(\omega_{i}\right)$ as shown in (25), (26) and (28) - (30) respectively. Note in both the cases, the total dc-link voltage $\left(v_{d c}\right)$ is independent of $\omega_{i}$. Therefore, the module dc-link voltage reference $v_{d c, m}{ }^{*}$ of boost-buck mode can also be independent of $\omega_{i}$ and be the same for all modules. The selection criterion of $v_{d c, m}{ }^{*}$ can be done using the equations (32) and (33) similar to what described in [29].

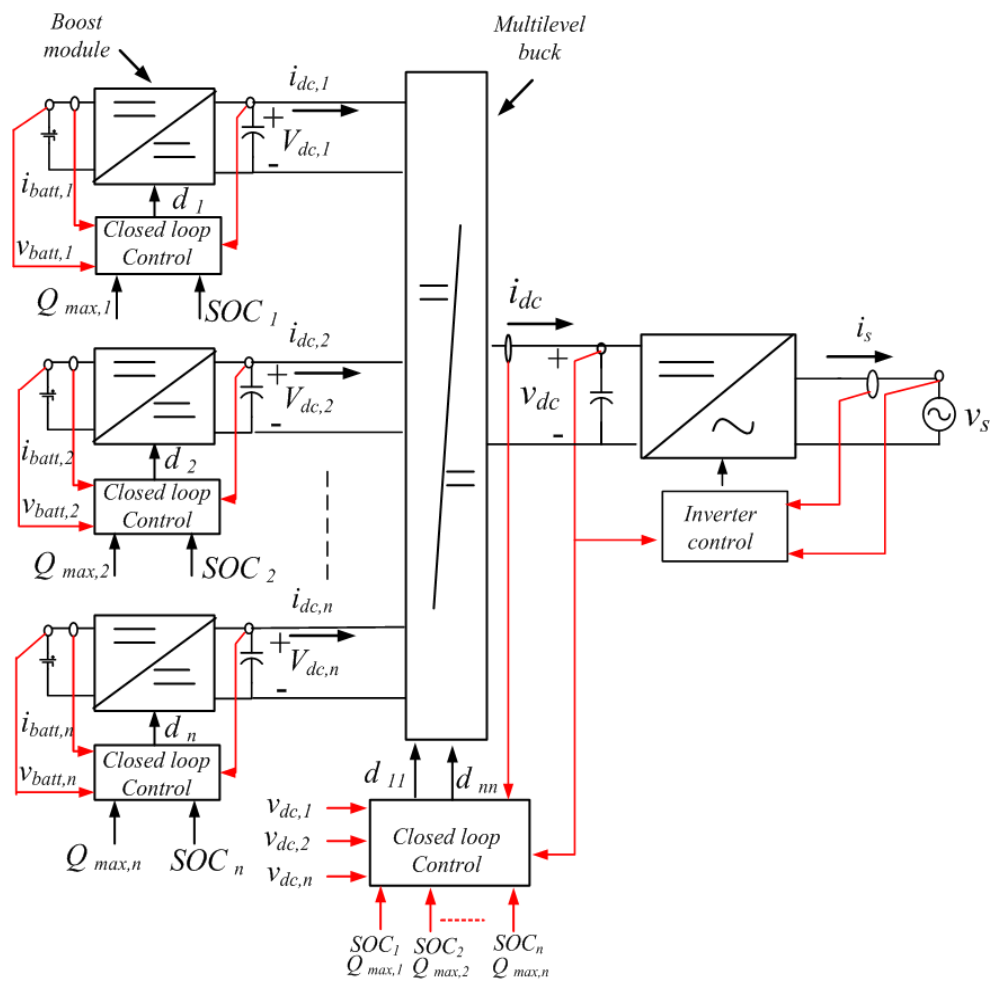

Fig. 12 Closed loop distributed control schematics of the modular converter

\section{Boost Mode:}

Power balance

$V_{d c, i} i_{d c}=V_{b a t t, i} i_{b a t t, i} \forall i=1 \ldots n$

Now, according to (19), $i_{\text {batt }, i}{ }^{*} \propto \omega_{i}$ implies $v_{d c, i}{ }^{*} \propto$ $v_{\text {batt }, i} \omega_{i} \forall i=1 \ldots n$ and therefore,

Now, $\sum v_{d c, i}{ }^{*}=v_{d c}{ }^{*}$

$v_{d c, i}{ }^{*}=v_{d c}{ }^{*} \frac{\omega_{i} v_{\text {batt }, i}}{\sum_{k=1}^{n} \omega_{k} v_{b a t t, k}} \forall i=1 \ldots n$ Or $D_{i}=1-\frac{V_{b a t t, i}}{V_{d c, i}}$

After generating these voltage references the closed loop control is performed according to Fig. 13(a).

Buck Mode:

Power balance -

$V_{\text {batt }, i}\left(D_{i i} I_{d c}\right)=V_{\text {batt }, i} i_{\text {batt }, i}$

Similarly according to (13), if $i_{\text {batt }, i}{ }^{*} \propto \omega_{i}$, then from (27) $D_{i i} \propto \omega_{i} \forall i=1 \ldots n$ and therefore, 
Using (11), $D_{i i}=\omega_{i} D_{a v} \frac{\left(\sum_{i=1}^{n} V_{b a t t, i}\right)}{\sum_{i=1}^{n} \omega_{i} V_{b a t t, i}} \forall i=1 \ldots n$

The overall effective duty ratio of the multilevel buck converter $\left(d_{a v}\right)$ is generated using central dc-link voltage loop as shown in Fig. 13(b).

\section{Boost-buck Mode:}

Power balance -

$V_{d c, m}\left(D_{i i} I_{d c}\right)=V_{b a t t, i} i_{b a t t, i}$

Similarly according to (13), if $i_{\text {batt }, i}{ }^{*} \propto \omega_{i}$, implies $D_{i i} \propto$ $\omega_{i} V_{b a t t, i} \forall i=1 \ldots n$ and therefore,

Now using (8), the following expression can be written,

$$
D_{i i}=n D_{a v} \frac{\omega_{i} V_{\text {batt }, i}}{\sum_{i=1}^{n} \omega_{i} V_{\text {batt }, i}} \forall i=1 \ldots n
$$

The overall $v_{d c}$ is independent of individual $D_{i i}$ but it is dependent on $\sum D_{i i}$ as explained in (31).

$V_{d c}=D_{a v}\left(\sum V_{d c, i}\right)$ Where $D_{a v}=\frac{\sum D_{i i}}{n}$

When all the modules operate in boost-buck mode, the sum of the total dc-link voltages $\left(\sum V_{d c, m}\right)$ should be greater than the dc-link voltage of the inverter $\left(V_{d c}\right)$ to allow the buck operation. Therefore, the module dc-link voltage reference can be selected by (32).

$n V_{d c, m}{ }^{*}>V_{d c}{ }^{*} \rightarrow \frac{V_{d c}{ }^{*}}{n}<V_{d c, m}{ }^{*} \leq V_{s w}$

In case, some of the modules (say $k$ number of modules) operate in idle mode, the voltage reference can be selected by (33).

$\frac{\left(V_{d c}{ }^{*}-\sum_{k \neq i} V_{b a t t, k}\right)}{(n-k)}<V_{d c, m}{ }^{*}<V_{S w} \forall i \neq k$

Moreover, it can be seen from Fig. 13 that the boost and the boost-buck both employ a voltage control loop to maintain the module dc-link voltage $\left(v_{d c, i}\right)$ whereas the multilevel buck mode does not need any control loop per module as each $v_{d c, i}$ is maintained by the corresponding $v_{\text {batt, } i}$ similar to that reported in [33]. On the other hand, the boost mode does not require any dedicated control loop to maintain the inverter dclink voltage because the central dc-bus is indirectly maintained by controlling module dc-link voltages while the boost- buck mode and buck mode both require a dedicated control loop to maintain the central dc-link voltage $v_{d c}$. Moreover, different control methods have different computational burden on the controller which can be expressed as a combination of number of control loops or number of integrators. Each inner current control loop in the control structure can be implemented through a proportional controller as shown in Fig. 13. Therefore, the buck mode has the least control complexity as it only requires a central bus voltage loop whereas the boost-buck mode has the highest complexity in terms of control loops as it requires the central dc-bus voltage loop as well as individual module voltage loops. The summary of the overall comparison from control point of views is presented in Table 2 .

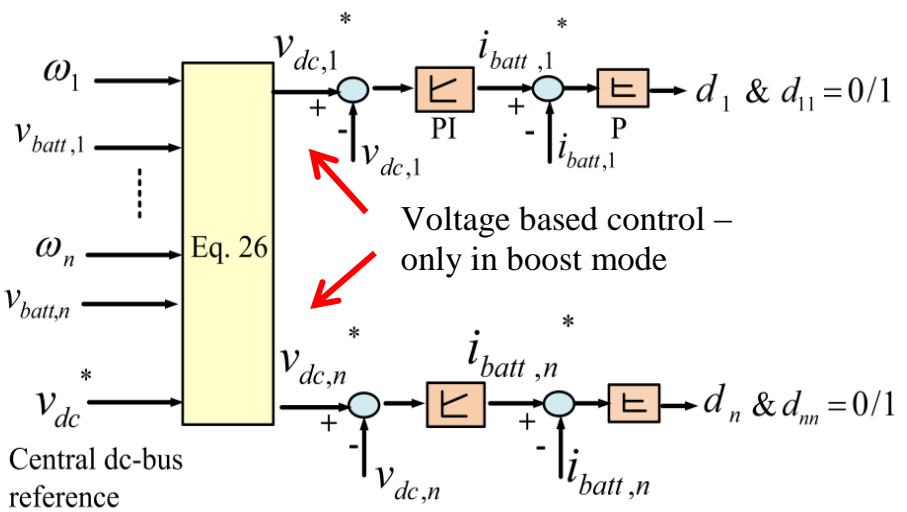

(a)

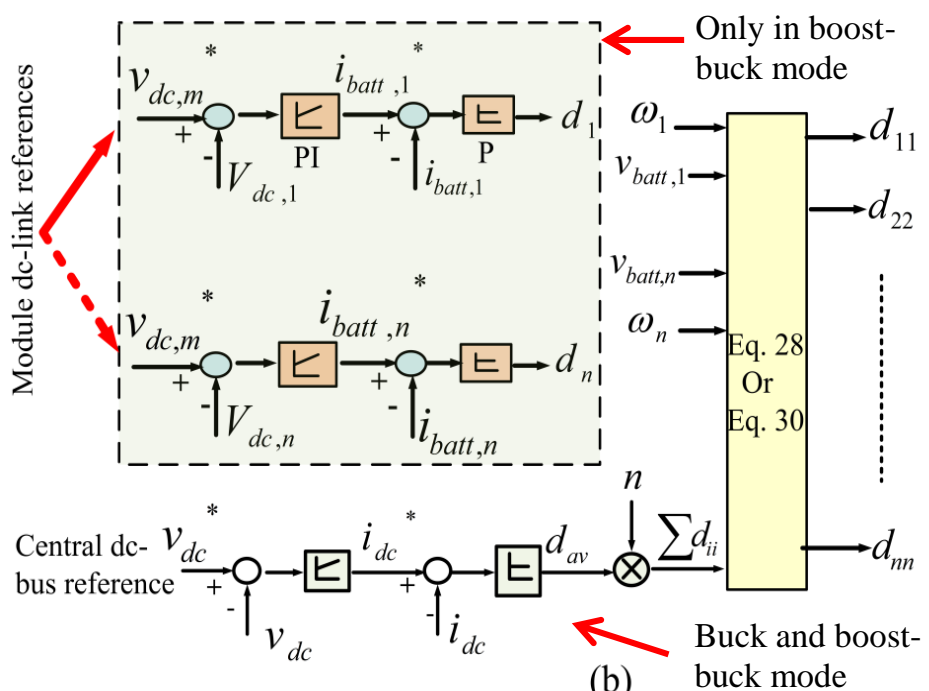

Fig. 13 DC-side control methods: a) boost mode, b) buck and boost-buck

mode

\section{Efficiency/Power Loss}

Different control modes use different switching combinations of the module H-bridge. The overall power loss of the configuration is a sum of the boost-multilevel dc-dc converter and the line side inverter. In boost mode module dc-link voltages are different to share the power while in the boostbuck mode, module dc-link voltages are maintained at the same level $(80 \mathrm{~V})$. It is to be noted that the inverter power loss or efficiency remains the same for all three operational modes for a given power level. Moreover, the same gate drive circuit can be used for all the devices in the modular converter, therefore, the gate drive losses can also be considered to be common across all the modes. For these reasons, only the dcside efficiency or power losses are considered as an indicative of the overall converter loss.

$\underline{\text { Mode }-1 \text { (boost mode) }}$ 
Power losses in this mode comprise of: a) losses in module boost inductor, b) conduction and switching losses of $S_{i}$ and $S_{i i}$, c) conduction losses in $T_{i}$ or $T_{i i}$, d) losses in the dc-link inductance $\left(L_{d c}\right)$. Expressions of the overall converter power losses in three modes are denoted by $P_{L 1}, P_{L 2}$ and $P_{L 3}$ for boost, buck and boost-buck mode respectively. Note: the conduction loss due to leakage resistance of the inductor has mainly been considered in this case neglecting the high frequency core losses. The power loss for the boost mode is presented in (32) where $R_{d s(o n)} T_{o n}, T_{\text {off }}$ are switch on-state resistance, turn ON and turn OFF time of $S_{i} / S_{i i}$ respectively.

TABLE 2 COMPARISON OF CONTROL METHODS IN DIFFERENT MODES

\begin{tabular}{|l|l|l|}
\hline Modes & $\begin{array}{l}\text { Control methods on the dc-side } \\
\text { within modular converter }\end{array}$ & $\begin{array}{l}\text { Total no. of control loops on } \\
\text { the dc-side }\end{array}$ \\
\hline Boost & $\begin{array}{l}V_{d c, i}=f\left(\omega_{i}\right) \rightarrow \text { only module } \\
\text { voltage based method }\end{array}$ & $n \rightarrow$ control loops \\
\hline $\begin{array}{l}\text { Multilevel } \\
\text { buck }\end{array}$ & $\begin{array}{l}D_{i i}=f\left(\omega_{i}\right) \rightarrow \text { distributed duty } \\
\text { ratio based method }\end{array}$ & $1 \rightarrow$ control loop \\
\hline $\begin{array}{l}\text { Boost- } \\
\text { multilevel } \\
\text { buck }\end{array}$ & $\begin{array}{l}V_{d c, m} \neq f\left(\omega_{i}\right) \text { and } \\
D_{i i}=f\left(\omega_{i}\right) \rightarrow \text { module voltage } \\
\text { and duty ratio based method }\end{array}$ & \\
\hline
\end{tabular}

$P_{L 1}=$

$\left(\sum i_{\text {batt }, i}^{2}\right) R_{L}+\left(\sum i_{\text {batt }, i}^{2}\right) R_{d s(o n)}+$

$\frac{1}{2}\left(\sum v_{d c, i} i_{\text {batt }, i}\right)\left(\frac{T_{o n}+T_{o f f}}{T_{s}}\right)+n i_{d c}{ }^{2} R_{d s(o n)}+i_{d c}{ }^{2} R_{L d c}$

$\underline{\text { Mode }-2 \text { (multilevel buck mode) }}$

The power losses in this mode comprises of following: a) losses in module boost inductor, b) conduction loss in $S_{i i}$, c) conduction losses and switching losses in $T_{i}$ and $T_{i i}$, d) losses in dc-link inductance $\left(L_{d c}\right)$. The expression of the power loss in mode is shown in (33). It can be clearly seen that expressions (32) and (33) are quite similar except the switching losses in $T_{i}, T_{i i}$ and $S_{i}, S_{i i}$. Since the same switches can be used in an H-bridge, the power loss/efficiency of these two modes is expected to be similar range.

$P_{L 2}=$

$\left(\sum i_{\text {batt }, i}^{2}\right) R_{L}+\left(\sum i_{\text {batt }, i}^{2}\right) R_{d s(o n)}+$

$\frac{1}{2}\left(\sum v_{\text {batt }, i} i_{\text {batt }, i}\right)\left(\frac{T_{o n}+T_{o f f}}{T_{s}}\right)+n i_{d c}{ }^{2} R_{d s(o n)}+i_{d c}{ }^{2} R_{L d c}$

Mode -3 (boost-modular multilevel buck mode)

The power losses in this mode comprises of following: a) losses in module boost inductor, b) conduction and switching losses in $S_{i}$ and $S_{i i}$, c) conduction losses and switching losses in $T_{i}$ and $\left.T_{i i}, \mathrm{~d}\right)$ losses in dc-link inductance $\left(L_{d c}\right)$. The expression of the power loss in mode is shown in (34).

$P_{L 3}=$

$\left(\sum i_{\text {batt }, i}^{2}\right) R_{L}+\left(\sum i_{\text {batt }, i}^{2}\right) R_{d s(o n)}+$

$$
\begin{aligned}
& \frac{1}{2}\left(\sum v_{d c, m} i_{b a t t, i}\right)\left(\frac{T_{o n}+T_{o f f}}{T_{s}}\right)+\frac{1}{2}\left(\sum v_{d c, m} I_{d c}\right)\left(\frac{T_{o n}+T_{o f f}}{T_{s}}\right)+ \\
& n i_{d c}{ }^{2} R_{d s(o n)}+i_{d c}{ }^{2} R_{L d c}
\end{aligned}
$$

\section{Comparison between boost and boost-buck mode}

It should be noted that power losses of boost and boost-buck mode can be compared together because both could be applicable for a similar operating condition, e.g. when $\sum v_{b a t t, i}<v_{d c}^{*}$ is satisfied. The central dc-link voltage has been considered as $150 \mathrm{~V}$ (same as experimental condition) for three modules. The control method in Fig. 13(a) has been applied in the boost mode and the method described in Fig. 13(b) has been applied in the boost-buck mode. Module dclink voltages are maintained at $80 \mathrm{~V}$ for the boost-buck mode and the overall dc-link voltage controller maintains $v_{d c}$ to $150 \mathrm{~V}$. The maximum boost ratio has been limited to 5 in this case. Calculated efficiency is plotted in Fig. 14 at various operating points or SOCs. The batteries in Table 1, semiconductor and passive components in Table 3 are used in the calculation. Efficiency is dependent on state-of-charge of the batteries. Therefore, efficiency for three different SOCs is shown for better understanding of the power loss variation. Different points on the same power level in Fig. 14 correspond to efficiencies at different SOCs as indicated. It is clear that a lower efficiency is obtained at a lower SOC because the module boost converter operates at a higher boost ratio at a lower $S O C$.

\section{Comparison between buck and boost-buck mode}

On the other hand, the buck and boost-buck modes could be compared together because they could be applicable for high voltage batteries or where a high number of modules is present where the condition $\sum v_{b a t t, i}>v_{d c}^{*}$ is fulfilled. Therefore, either a large number of relative low voltage $(3 \mathrm{~V} / 12 \mathrm{~V}$ etc.) modules or a low number of high voltage $(200 \mathrm{~V} / 400 \mathrm{~V}$ etc.) modules is required as a result of this voltage constraint. In the present case, 20 modules of $12 \mathrm{~V}, 10 \mathrm{Ah}$ lead acid batteries (module -1 in Table 1$)$ have been considered $\left(\sum v_{\text {batt }, i}=\right.$ $240 \mathrm{~V}$ ) for theoretical efficiency comparison between these modes. The central dc-link voltage has been considered to be $150 \mathrm{~V}$ for single phase grid connection as earlier. Therefore, $240 \mathrm{~V}$ to $150 \mathrm{~V}$ buck operation has been simulated in the buck mode. The control method in Fig. 13(b) has been applied to maintain the dc-link voltage. The efficiency comparison result is shown in Fig. 15 for the same set of SOC values used in Fig. 14.

TABLE 3 COMPONENTS AND THEIR SPECIFICATIONS USED IN THE STUDY

\begin{tabular}{|l|l|}
\hline $\begin{array}{l}\text { LV Trench MOSFET for H-bridge dc- } \\
\text { dc modules }\end{array}$ & $\begin{array}{l}100 \mathrm{~V} 40 \mathrm{~A}-R_{d s(o n)}=8 \mathrm{~m} \Omega, \\
(\text { FDPF085N10A) }\end{array}$ \\
\hline Central dc-link voltage $\left(V_{d c}\right)$ & $150 \mathrm{~V}$ \\
\hline Boost inductors of dc-dc modules $(L)$ & $1.5 \mathrm{mH}, 15 \mathrm{~A}, R_{L}=40 \mathrm{~m} \Omega$ \\
\hline dc-link inductor $\left(L_{d c}\right)$ & $1.5 \mathrm{mH}, 15 \mathrm{~A}, R_{L}=40 \mathrm{~m} \Omega$ \\
\hline Switching frequency of dc-dc modules & $10 \mathrm{kHz}$ \\
\hline
\end{tabular}




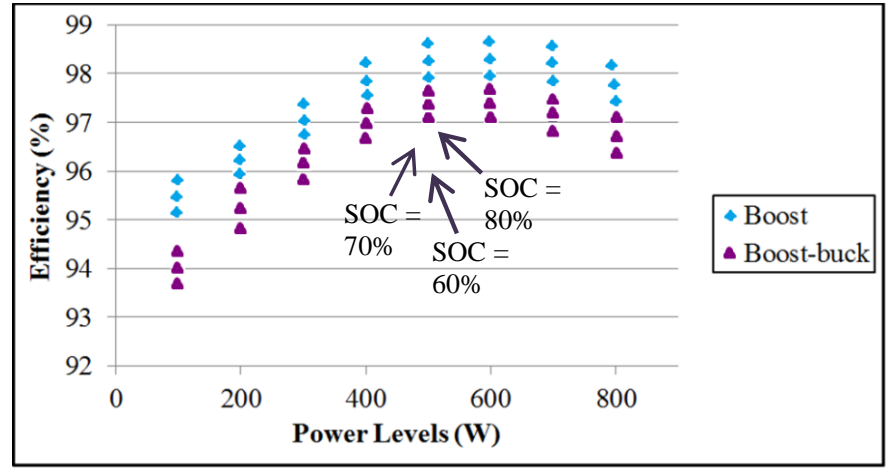

Fig. 14 Theoretical efficiency comparison between boost and boost-buck mode at different SOCs

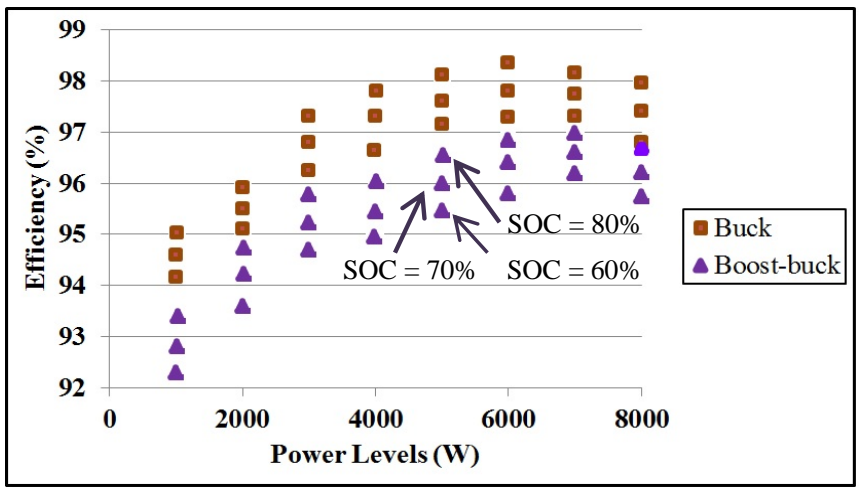

Fig. 15 Theoretical efficiency comparison buck and boost-buck mode at different SOCs

\section{Capacitor ripple current}

Capacitor ripple current is another important criterion of comparison as described in section II. It was found that the boost-buck could incur higher or lower ripple current depending on the battery weighting factor or hybrid battery configurations. There is a wide variation of ripple current in boost-buck compared to the boost/buck mode. This means when the converter is operated in boost-buck mode, it can reduce the overall reliability because the module capacitors could undergo increased current stress compared to other modes.

\section{E. Overall Comparison}

Table 4 shows the summary of the overall comparison. It can be seen from Table 4 that the boost-buck mode is more versatile in terms of application and control range. However, it gives rise to lower conversion efficiency (around $1-2 \%$ lower) and higher capacitor ripple current compared to other modes. In an application where a widely different batteries is present (widely different weighting factors), the boost-buck control mode should be the most practical mode of operation from the battery utilisation point of views. However, in the specific application where all LV batteries or all HV modules with similar characteristics (or similar weighting factors) are present, the boost or buck mode should be chosen over the boost-buck mode in order to achieve higher converter efficiency and higher reliability. Therefore, the choice of control mode is dependent on the weighting factors as well as on the application. A brief guideline on mode selection is presented in Fig. 16. The designer selection is mainly influenced by two major factors: a) the overall battery side voltage compared to the central dc-link voltage, $b$ ) the desired distribution of module currents.

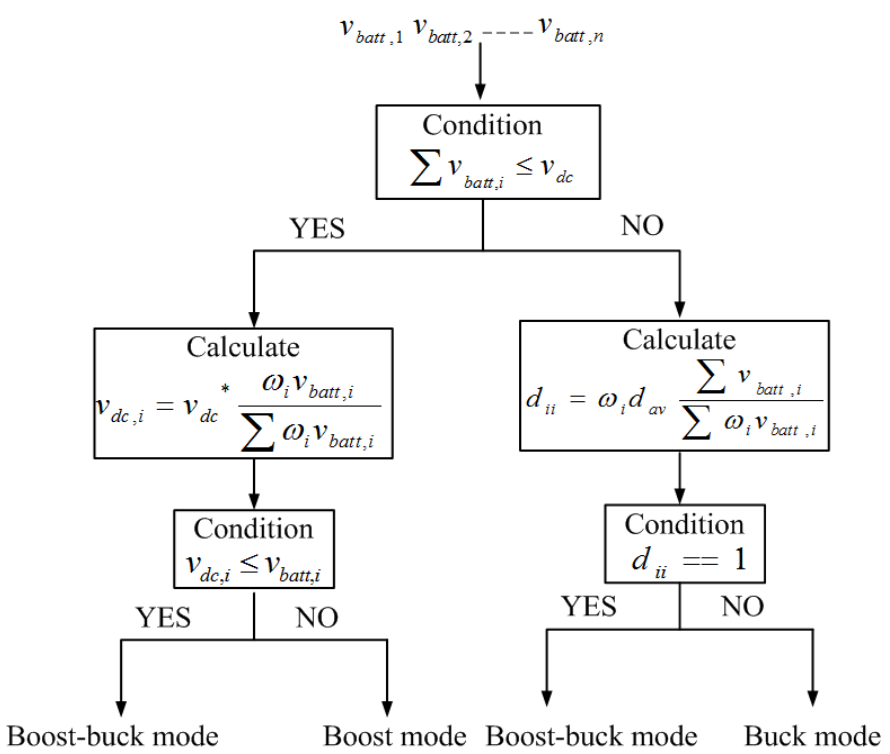

Fig. 16 A brief guideline on selecting mode of the converter

\section{EXPERIMENTAL VALIDATIONS}

A four converter module based scale-down hybrid battery storage system prototype has been built as shown in Fig. 17 using the batteries described in Table 1 . The figure clearly shows three types of batteries along with four converter modules. The overall system is tested at a $100 \mathrm{~V}, 500 \mathrm{~W}$ power level by connecting to $230 \mathrm{~V}, 50 \mathrm{~Hz} 1-\Phi$ real power grid system through a Variac to validate different modes. The overall dcbus voltage $\left(v_{d c}\right)$ for the line side inverter was controlled to $150 \mathrm{~V}$ all the time irrespective of operational modes. Under the test condition $\sum v_{b a t t, i}<v_{d c}$ is fulfilled. As a result mainly boost and boost-buck mode could be compared according to Table 4. Moreover, there is a similarity between boost- buck and buck mode in terms of switching operation. Additionally, testing a buck mode requires a high number of battery modules to match with the grid voltage, therefore, the boost mode and boost- buck mode only have been validated and compared in the laboratory conditions.

The whole validation has been presented in four stages: $A$ ) module inductor and capacitor ripples to validate the analysis described in section II, $B$ ) grid connected operation, $C$ ) control methods and control range to validate the methods presented in section IIIA and IIIB, D) converter efficiency in two different modes at various SOCs to validate the claim in section IIIC.

\section{A. Module Inductor and Capacitor Ripple Current}

Inductor and capacitor currents of one module (module 4) were measured whose steady current was about $5 \mathrm{~A}$ to compare with the analysis presented in section II. The boost inductor current $\left(i_{\text {batt }, 4}\right)$ and the dc-link inductor current $\left(i_{d c}\right)$ are presented along with the capacitor current in Fig. 18. Note the measured waveforms are very similar to section II. 
This article has been accepted for publication in a future issue of this journal, but has not been fully edited. Content may change prior to final publication. Citation information: DOI 10.1109/JESTPE.2015.2460334, IEEE Journal of Emerging and Selected Topics in Power Electronics

IEEE JOURNAL OF EMERGING AND SELECTED TOPICS IN POWER ELECTRONICS

TABLE 4 A SUMMARY OF OVERALL COMPARISON OF DIFFERENT MODES

\begin{tabular}{|l|l|l|l|l|l|}
\hline Modes & $\begin{array}{l}\text { Application } \\
\text { range }\end{array}$ & $\begin{array}{l}\text { Operational } \\
\text { range/Envelope per } \\
\text { module }\end{array}$ & dc-side Efficiency & $\begin{array}{l}\text { Control } \\
\text { complexity }\end{array}$ & $\begin{array}{l}\text { Capacitor ripple current } \\
\text { variation }\end{array}$ \\
\hline Boost & $\sum v_{b a t t, i}<v_{d c}^{*}$ & $\begin{array}{l}\text { Narrow } \\
i_{b a t t, i} \geq i_{d c}\end{array}$ & $\begin{array}{l}\text { High } \\
\text { Approx. }(97-98 \%)\end{array}$ & $\begin{array}{l}\text { High } \\
n \text { control loops }\end{array}$ & $\begin{array}{l}\text { Potentially small and narrow } \\
\text { variation }\end{array}$ \\
\hline Buck & $\sum v_{b a t t, i}>v_{d c}^{*}$ & $\begin{array}{l}\text { Narrow } \\
i_{b a t t, i} \leq i_{d c}\end{array}$ & $\begin{array}{l}\text { High } \\
\text { Approx. }(97-98 \%)\end{array}$ & $\begin{array}{l}\text { Low } \\
1 \text { control loop }\end{array}$ & $\begin{array}{l}\text { Potentially small and narrow } \\
\text { variation }\end{array}$ \\
\hline Boost-buck & Any & $\begin{array}{l}\text { Wide } \\
i_{b a t t, i} \leq \frac{v_{S w}}{v_{b a t t, i}} I_{d c}\end{array}$ & $\begin{array}{l}\text { Low } \\
\text { Approx. }(94-95 \%)\end{array}$ & $\begin{array}{l}\text { High } \\
n+1 \text { control loops }\end{array}$ & $\begin{array}{l}\text { Potentially high ripple } \\
\text { current and more wider } \\
\text { variation }\end{array}$ \\
\hline
\end{tabular}

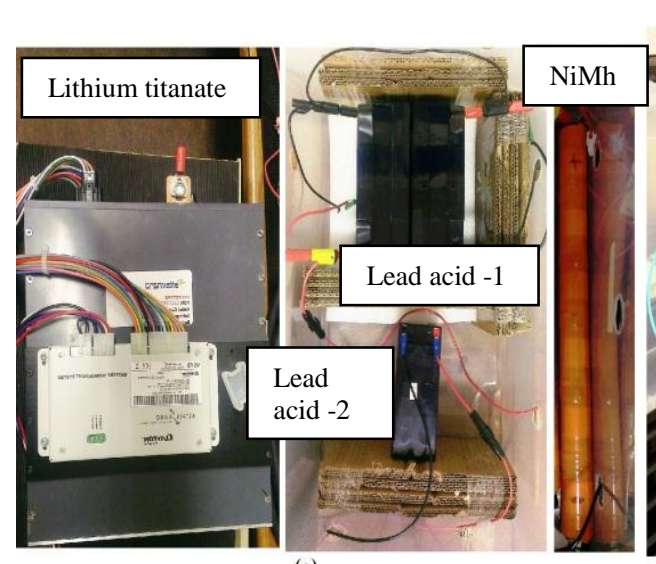

(a)

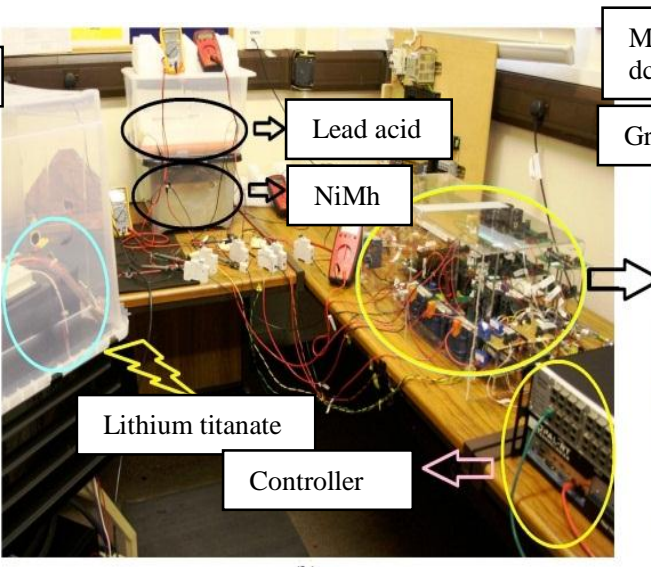

(b)

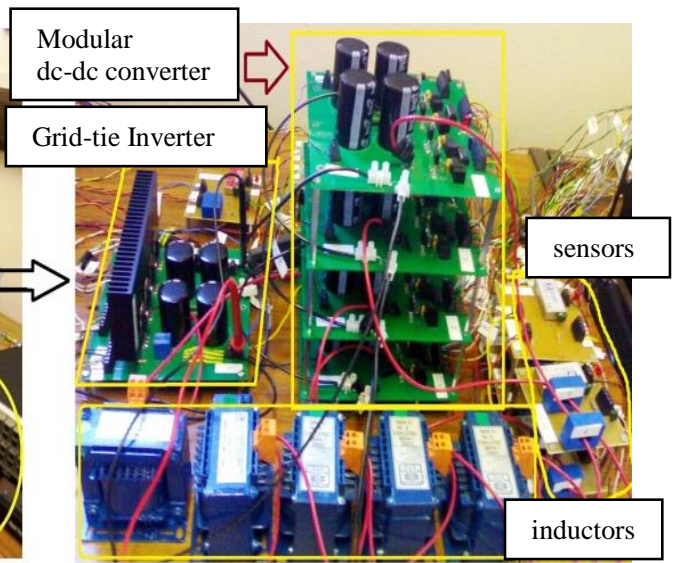

(c)

Fig. 17 Laboratory build prototype: a) hybrid batteries, b) overall set-up, c) modular dc-dc converter, grid-tie inverter, inductor and sensors

The comparison between the calculated and measured ripple currents is shown in Table 5 at an instant of time for both the modes. The measured result has been presented for both situations when $D_{44}>D_{4}$ and $D_{44}<D_{4}$. Note that measured capacitor currents agree with the calculation and the analysis presented in section - II.

Moreover, the capacitor current ripple of module -4 has been measured and compared throughout a discharging cycle against the calculated values. The results have been shown in two stages: a) for the boost-buck mode shown in Fig. 19 and b) for the boost mode shown in Fig. 20. A 3D plot has been presented for the boost-buck mode because the RMS current $i_{\text {batt, },}$ ripple depends on two different duty ratios according to (18). On the other hand, a 2D plot is presented for the boost mode $\boldsymbol{i}_{d c}$ because the ripple depends on one duty ratio according to (8). Note the ripple current for the boost mode rapidly decreases and then increases and also reaches to zero within $0.6<\mathrm{D} 4<$ 0.8 because of presence of $D$ and $(1-D)$ term in the expression. It can be seen that experimental values are within $\pm 10 \%$ compared to their calculated values. This is due to the accuracy with which the measurements are taken. This validates the analysis presented in Fig. 6 .

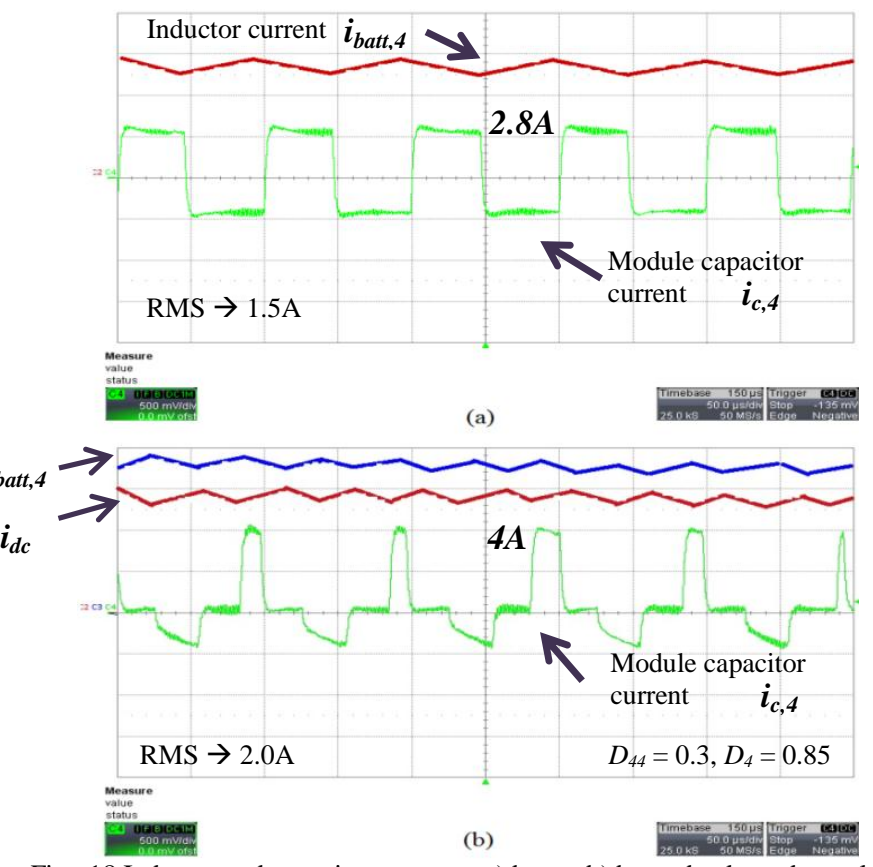

Fig. 18 Inductor and capacitor currents: a) boost, b) boost-buck mode: scale 50 us/div 2A/div 


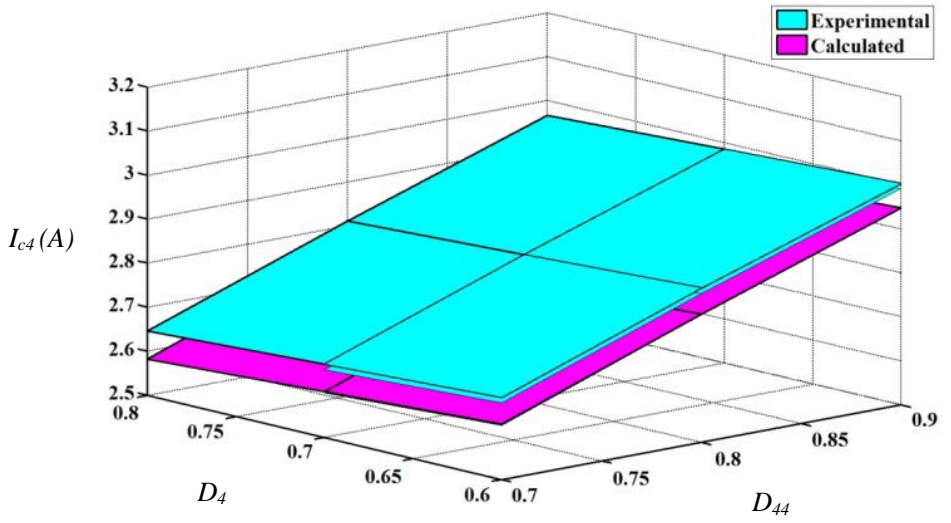

Fig. 19 Calculated and experimental rms capacitor current ripple comparison for the boost-buck mode within a certain band of duty cycles

TABLE 5 CALCULATED AND MEASURED MODULE CAPACITOR RIPPLE CURRENTS

\begin{tabular}{|l|l|l|l|l|}
\hline $\begin{array}{l}\text { Operating condition } \\
\text { for module -4 at an } \\
\text { instant }\end{array}$ & $\begin{array}{l}\text { Calculated rms } \\
\text { capacitor ripple current } \\
\text { (A) }\end{array}$ & $\begin{array}{l}\text { Experimentally measured } \\
\text { rms ripple current (A) }\end{array}$ \\
\hline$D_{4}(0.3)<D_{44}$ & $\begin{array}{c}\text { Boost } \\
(0.85)\end{array}$ & $\begin{array}{l}\text { Boost- } \\
\text { buck }\end{array}$ & $\begin{array}{l}\text { Boost } \\
1.5 \mathrm{~A}\end{array}$ & $\begin{array}{l}\text { Boost-buck } \\
1.95 \mathrm{~A}\end{array}$ \\
\hline$D_{4}(0.35)>D_{44}$ & Boost-buck & Boost & Boost- & Boost \\
$(0.25)$ & $1.9 \mathrm{~A}$ & $1.6 \mathrm{~A}$ & buck & $1.7 \mathrm{~A}$ \\
& & & $2.1 \mathrm{~A}$ & \\
\hline
\end{tabular}

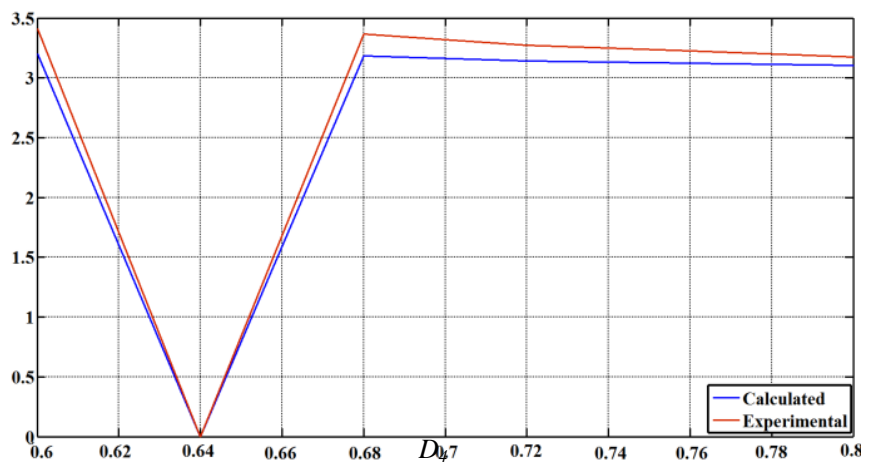

Fig. 20 Calculated and experimental rms capacitor current ripple comparison for the boost mode within $0.6-0.8$ duty cycle range

\section{B. Grid connected operation}

Fig. 21 shows the validation of grid side and dc-link control system operation at a moment in time when the inverter is switched from charging to discharging mode. It can be seen the change of phase angle the line side current with respect to the voltage when the dc-link current $\left(I_{d c}\right)$ moves from negative to positive. It can be seen that these results are very similar to the simulation results presented in Fig. 9 and Fig. 10. Moreover, the total DC-link voltage $\left(v_{d c}\right)$ stays constant during the transition. This demonstrates that all module controllers are working as expected. Note that the common dc-link current $\left(i_{d c}\right)$ has a double frequency (here $100 \mathrm{~Hz}$ ) component in the boost mode while boost-buck mode does not have such an issue. This is because there is a dc-link current controller present in the boost-buck mode (Fig. 13) and a $100 \mathrm{~Hz}$ notch filter is used in the outer voltage loop which removes this component being propagated in the module current. However, there is no dc-link current control possible in the boost mode.

Fig. 22 shows the difference of switching operation between these modes where the voltage between the points ' $A$ ' and ' $B$ ' of Fig. 1 has been presented. It is important to note that boost mode has a continuous voltage across $A B$ while the boost-buck mode has a switched voltage (discontinuous waveform) across these points because of PWM nature of $T_{i}, T_{i i}(\forall i=1 \ldots 4)$ in Fig. 1. Multilevel operation is also displayed.

\section{Control Range and Control Methods}

Control range is different in two modes. Fig. 23 presents experimental results of current sharing using boost and boostbuck mode to demonstrate the range of control. It can be seen from Fig. 23(a) that the boost mode cannot fully utilise the modules because the module currents are limited by the common dc-link current $i_{\mathrm{dc}}$ at the lower end which contains $100 \mathrm{~Hz}$ component in the 1- $\varphi$ grid system. Fig. 23(b) shows distinct module utilisation where module currents are not limited at the lower end as explained in the section IIIA. However, the similar result is true for charging condition also. This shows the effectiveness of the boost-buck mode when a widely different batteries is present.

In order to validate different control methods, module dclink voltage dynamics during charging to discharging transition has been presented in Fig. 24 because these voltages are controlled in different ways in the boost and boost-buck mode. Three module voltages are shown along with the grid current. It can be seen that module dc-link voltages are different in the boost mode and distribute among themselves to keep the central link voltage constant. For example, module -1 voltage changes from $75 \mathrm{~V}$ to $60 \mathrm{~V}$ while the module -3 voltage moves from $45 \mathrm{~V}$ to $65 \mathrm{~V}$. On the other hand, all the module voltages remain at $80 \mathrm{~V}$ in the boost-buck mode as shown in Fig. 24.

\section{Power loss/Efficiency}

Power loss in the modular converter was measured at the different power levels for the boost and boost-buck mode at the different battery operating points or SOCs. In boost mode module dc-link voltages are controlled according to the SOCs but in the boost-buck mode dc-link voltages are controlled at $80 \mathrm{~V}$ irrespective of their input voltage and the central dc-link voltage $\left(v_{d c}\right)$ is maintained at $150 \mathrm{~V}$. The duty ratio $d_{i i}$ is controlled according the SOC. This is done through Fig. 25 where the experimental comparison between the two modes is presented at various SOCs. Note the measured efficiency is similar to the calculated efficiency in Fig. 14. The dotted points of the curve show the efficiency at different SOC at the same power level. It is found that the boost-buck mode has higher losses and lower efficiency e.g. $1-2 \%$ at all power levels compared to the boost mode as expected because the boost-buck mode incurs higher switching loss compared to the boost mode of operation. However, the difference between the modes comes down at higher power levels. 
This article has been accepted for publication in a future issue of this journal, but has not been fully edited. Content may change prior to final publication. Citation information: DOI 10.1109/JESTPE.2015.2460334, IEEE Journal of Emerging and Selected Topics in Power Electronics

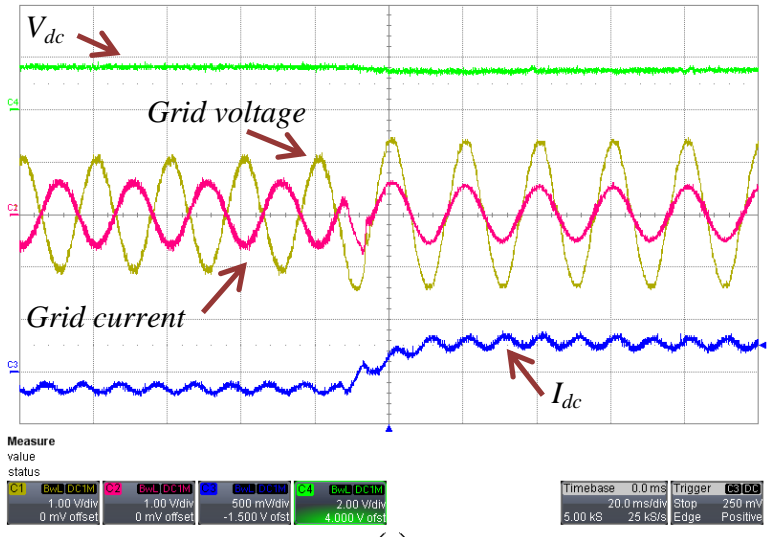

(a)

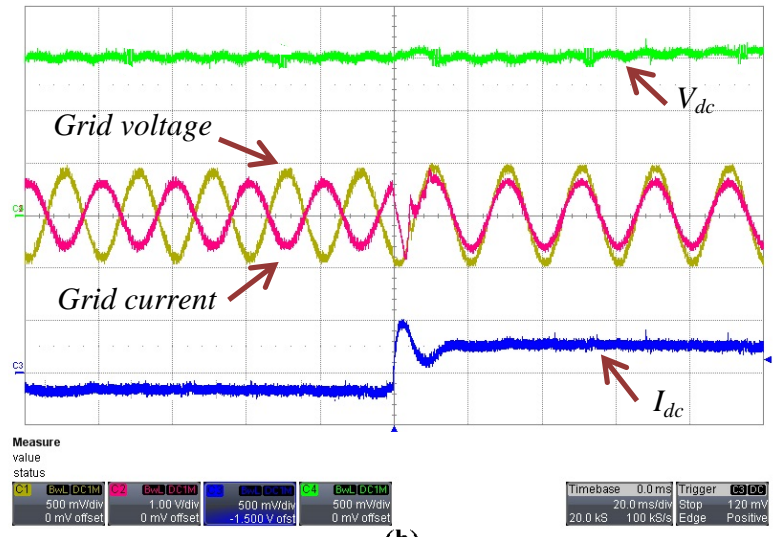

(b)

Fig. 21 Grid connected operation switching from charging to discharging mode: a) dynamics in boost mode and b) dynamics in boost-buck mode: scale time $20 \mathrm{~ms} / \mathrm{div}$, grid voltage $100 \mathrm{~V} / \mathrm{div}$, grid current $10 \mathrm{~A} / \mathrm{div}$, dc-link voltage $200 \mathrm{~V} / \mathrm{div}$, dc-link current $5 \mathrm{~A} / \mathrm{div}$

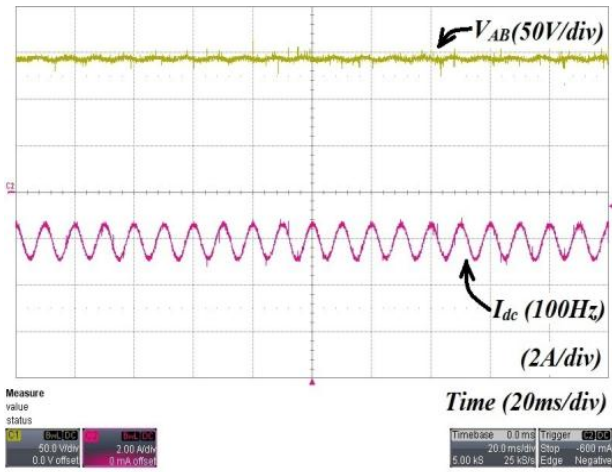

(a)

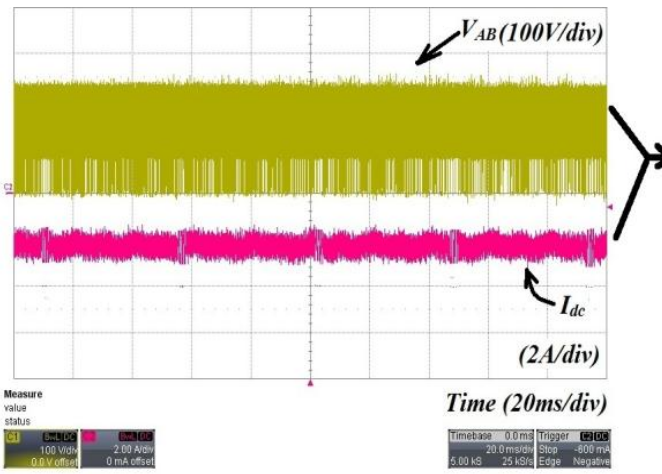

(b)

Fig. 22 Measured voltages between the points 'A' and 'B' of the converter in Fig 1: a) boost mode, b) boost-buck mode: scale time 20ms/div dc-link voltage $200 \mathrm{~V} / \mathrm{div}$, dc-link current $2 \mathrm{~A} / \mathrm{div}$

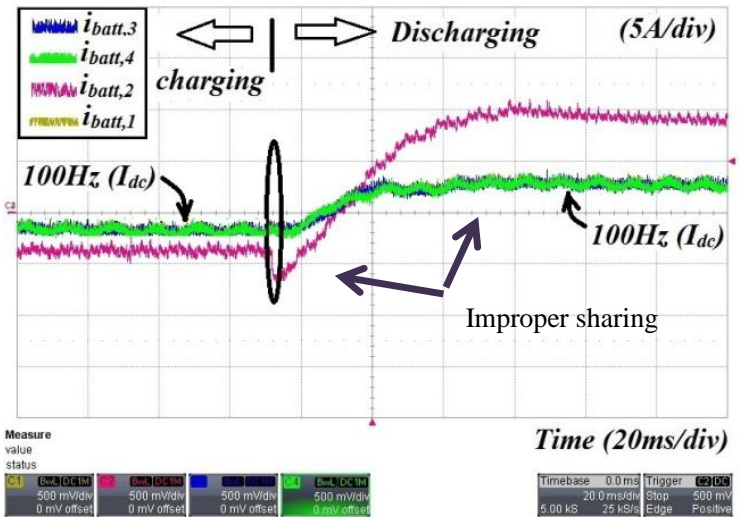

(a)

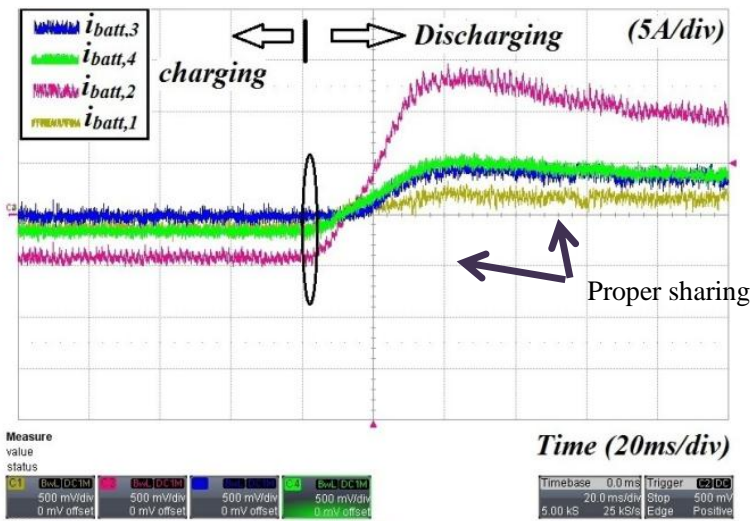

(b)

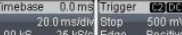

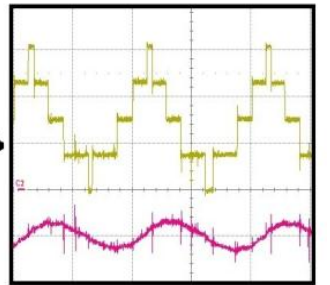

Time (50us/div)

Fig. 23 Current sharing; a) boost, b) boost-buck mode; scale 20ms/div, 5A/div

TABLE 6 CALCULATED AND MEASURED POWER LOSS DISTRIBUTION WITHIN THE DC-SIDE MODULAR CONVERTER

\begin{tabular}{|l|l|l|l|l|l|l|l|l|}
\hline Modes & \multicolumn{2}{|l|}{ Conduction loss } & \multicolumn{2}{l|}{ Switching loss } & \multicolumn{2}{l|}{ Total loss } \\
\hline \multirow{2}{*}{ Boost } & Calculated & Measured & Calculated & Measured & Calculated & Measured & Calculated & Measured \\
\cline { 2 - 9 } & $3.5 \mathrm{~W}$ & $\approx 4 \mathrm{~W}$ & $1.3 \mathrm{~W}$ & $\approx 2 \mathrm{~W}$ & $7.5 \mathrm{~W}$ & $\approx 9 \mathrm{~W}$ & $12.3 \mathrm{~W}$ \\
\hline $\begin{array}{l}\text { Boost- } \\
\text { buck }\end{array}$ & Calculated & Measured & Calculated & Measured & Calculated & Measured & Calculated & Measured \\
\cline { 2 - 8 } & $3.5 \mathrm{~W}$ & $\approx 5 \mathrm{~W}$ & $3 \mathrm{~W}$ & $\approx 4.0 \mathrm{~W}$ & $7.5 \mathrm{~W}$ & $\approx 9 \mathrm{~W}$ & $14 \mathrm{~W}$ & $\approx 18 \mathrm{~W}$ \\
\hline
\end{tabular}

This is mainly because at higher power levels the conduction losses in the devices dominate compared to the switching losses.
The power losses in different parts of the converter have also presented to justify the theoretical analysis. The power losses have been measured using high precision LeCroy 
oscilloscopes $(1 \mathrm{GHz})$ and a thermal camera in the laboratory. A detailed loss distribution is presented at $500 \mathrm{~W}$ power level in Table 6 along with calculated power losses using expressions (32) - (34). Fig. 26 shows the measured power loss in each part of the converter. The practical measurement shows a higher power losses compared to the theory because of parasitic components, stray losses in the power circuit and the accuracy of the equipment used. Moreover, the precise measurement of switching losses and conduction losses in the semiconductor switches under operating conditions is difficult because of their dependency with the temperature. However, in the present case, measured losses are found to be within $\pm 10 \%$ compared to the theoretical calculation. The boostbuck mode incurs significantly higher switching loss compared to the boost mode of operation while the other losses remain in the comparable range.

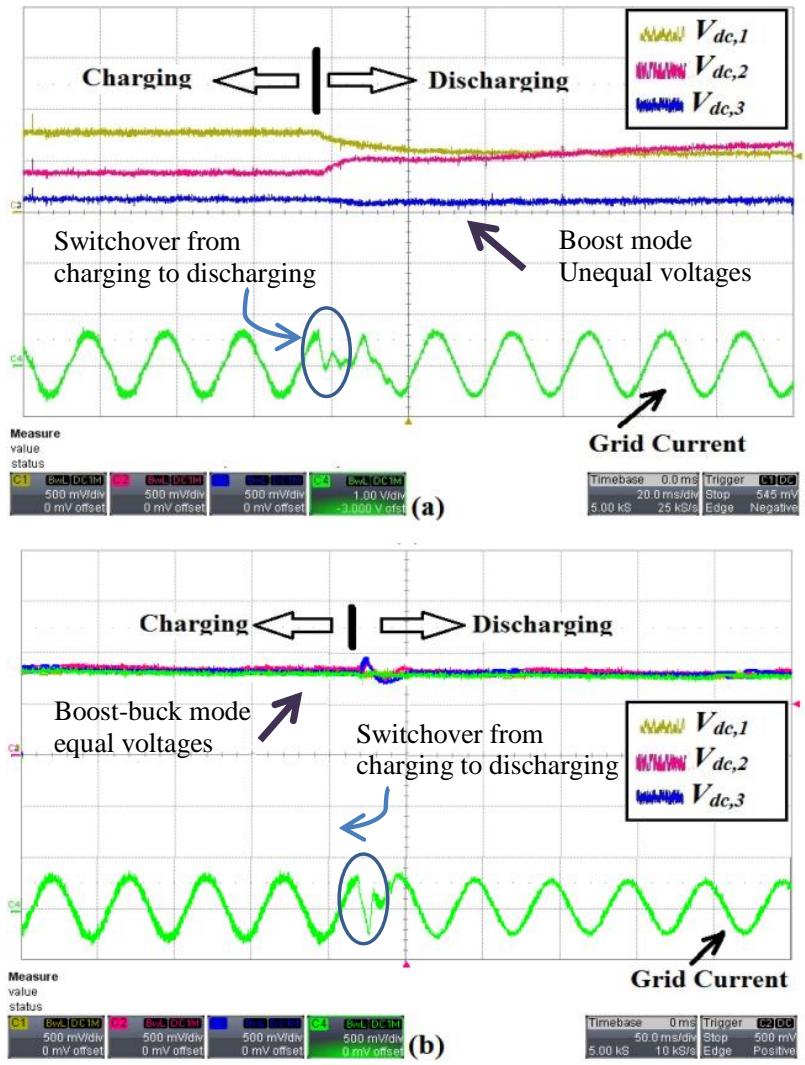

Fig. 24 Comparison of control methods: module dc-link voltage $\left(V_{d c, i}\right)$ dynamics in boost and boost-buck modes: scale $20 \mathrm{~ms} / \mathrm{div}, 50 \mathrm{~V} / \mathrm{div}$

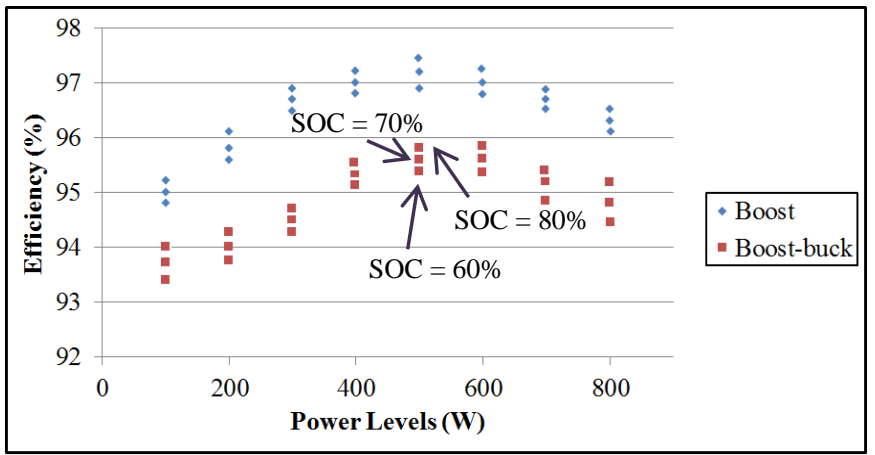

Fig. 25 Measured efficiency comparison between boost and boost-buck mode

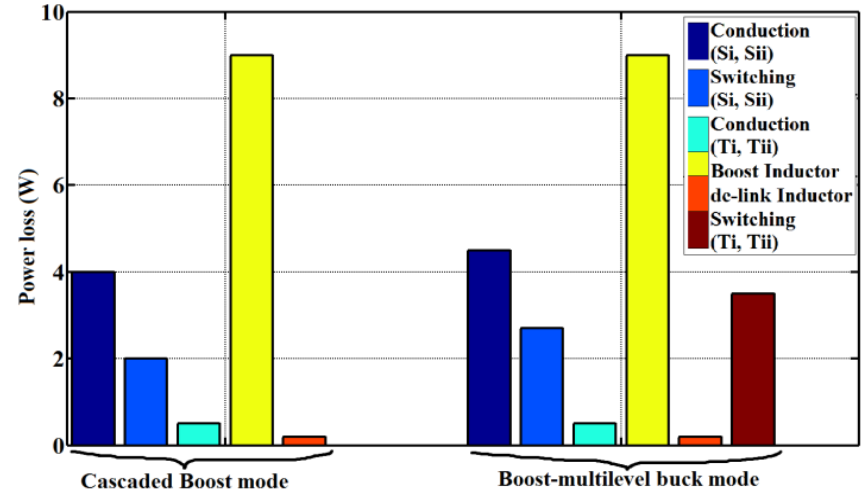

Fig. 26 Experimental loss distribution at 500W in boost and boost-buck mode

\section{DISCUSSION AND CONCLUSION}

The paper shows the feasibility and practicality of a modular hybrid energy storage system consisting of widely different battery types within the same converter. Different operational modes of the converter have been explored, analysed, compared and experimentally validated. The proposed converter is found to be universal in nature which can be operated in: boost, buck and boost-buck mode from input to output using an appropriate combination of module switches. It was found from the analysis and experimental results that a trade-off exists between the efficiency, control complexity and operational range. For example, the boost or buck mode, have narrow operating envelopes but higher efficiency compared to the boost-buck mode while the latter mode has a wider operational flexibility which can utilise more widely different battery types in an appropriate manner. On the other hand, the boost and boost-buck mode have higher computational burden on the controller compared to the buck mode due to the presence of multiple control loops. The boost-buck mode may have a higher capacitor current ripple compared to the other modes which can reduce the reliability of module capacitors.

Moreover, the converter cost is also dependent on the choice of operating modes because different modes could use different number of $\mathrm{I} / \mathrm{O}$ ports, sensors and controller. For example if the converter is to be operated in the boost-buck mode, it demands extra PWM signals/IO ports and extra sensors which can increase the converter cost. On the other hand, if the converter is to be operated either in buck or boost mode, the overall converter cost could be reduced but at the expense of reduced control flexibility. A mode selection needs to be performed depending on designer's requirement and choice of range of battery sizes.

Follow on research is needed to look at how a choice of battery size envelope relating to current and voltage limits can be used to choose operating modes and set capacitor and inductor values in more practical large scale set-ups.

\section{ACKNOWLEDGEMENT}

The authors would like to thank Prof. David Stone of the University of Sheffield, UK for his valuable suggestions and the battery manufacturer Altairnano for providing a Lithium Titanate $\left(\mathrm{Li}_{2} \mathrm{TiO}_{3}\right)$ battery module in experimental validations. 


\section{REFERENCES}

[1] http://www.cnet.com/uk/news/nissan-leaf-batteries-seek-second-life-ashome-storage/ [available online] referenced 22.05/15

[2] http://www.autonews.com/article/20130506/OEM05/305069985/2ndlives-for-ev-batteries-could-cut-prices [available online] referenced $22.05 / 15$

[3] Strickland, D.; Chittock, L.; Stone, D.A.; Foster, M.P.; Price, B., "Estimation of Transportation Battery Second Life for Use in Electricity Grid Systems," IEEE Trans. Sustain. Energy, vol.5, no.3, pp.795, 803, July 2014.

[4] Hart, P.J.; Kollmeyer, P.J.; Juang, L.W.; Lasseter, R.H.; Jahns, T.M., "Modeling of second-life batteries for use in a CERTS microgrid," in Proc. IEEE Power and Energy Conf. at Illinois (PECI), vol., no., pp.1,8, Feb. 28 2014-March 12014.

[5] Gladwin, D.T.; Gould, C.R.; Stone, D.A.; Foster, M.P., "Viability of "second-life" use of electric and hybrid electric vehicle battery packs," in Proc. 39 $9^{\text {th }}$ Annual Conf. Industrial Electronics Society, IECON, vol., no., pp.1922,1927, 10-13 Nov. 2013

[6] "Global EV outlook understanding the Electric Vehicle Landscape to 2020" http://www.iea.org/publications/globalevoutlook_2013.pdf

[7] Mukherjee, N.; Strickland, D., "Second life battery energy storage systems: Converter topology and redundancy selection," in Proc. 7th IET International Conf. on Power Electronics, Machines and Drives (PEMD), , vol., no., pp.1,6, 8-10 April 2014.

[8] Birkl, C.R.; Frost, D.F.; Bizeray, A.M.; Richardson, R.R.; Howey, D.A., "Modular converter system for low-cost off-grid energy storage using second life li-ion batteries," in Proc. IEEE Global Humanitarian Technology Conf. (GHTC), vol., no., pp.192,199, 10-13 Oct. 2014.

[9] Mukherjee, N.; Strickland, D.; Varnosfaderani, M.A., "Adaptive control of hybrid battery energy storage systems under capacity fade," in Proc. 16th European Conf. on Power Electronics and Applications (EPE'14ECCE Europe), vol., no., pp.1,10, 26-28 Aug. 2014.

[10] Hagiwara, M.; Akagi, H., "Experiment and Simulation of a Modular Push-Pull PWM Converter for a Battery Energy Storage System," IEEE Trans. Ind. Appl., vol.50, no.2, pp.1131,1140, March-April 2014.

[11] Soong, T.; Lehn, P.W., "Evaluation of Emerging Modular Multilevel Converters for BESS Applications," IEEE Trans. Power Del., vol.29, no.5, pp.2086, 2094, Oct. 2014.

[12] Kawakami, N.; Ota, S.; Kon, H.; Konno, S.; Akagi, H.; Kobayashi, H.; Okada, N., "Development of a 500-kW Modular Multilevel Cascade Convertor for Battery Energy Storage Systems," IEEE Trans. Ind. Appl., vol.50, no.6, pp.3902,3910, Nov.-Dec. 2014.

[13] Vasiladiotis, M.; Rufer, A., "Analysis and Control of Modular Multilevel Converters with Integrated Battery Energy Storage," IEEE Trans. Power Electron. vol.30, no.1, pp.163, 175, Jan. 2015.

[14] Feng Gao; Lei Zhang; Qi Zhou; Mengxing Chen; Tao Xu; Shaogang Hu, "State-of-charge balancing control strategy of battery energy storage system based on modular multilevel converter," in Proc. IEEE Energy Conversion Congress and Exposition (ECCE), vol., no., pp.2567,2574, 14-18 Sept. 2014.

[15] Ur Rehman, M.M.; Evzelman, M.; Hathaway, K.; Zane, R.; Plett, G.L.; Smith, K.; Wood, E.; Maksimovic, D., "Modular approach for continuous cell-level balancing to improve performance of large battery packs," in Proc. IEEE Energy Conversion Congress and Exposition (ECCE), vol., no., pp.4327,4334, 14-18 Sept. 2014.

[16] Zedong Zheng; Kui Wang; Lie Xu; Yongdong Li, "A Hybrid Cascaded Multilevel Converter for Battery Energy Management Applied in Electric Vehicles," IEEE Trans. Power Electron, vol.29, no.7, pp.3537,3546, July 2014

[17] Inthamoussou, F.A.; Pegueroles-Queralt, J.; Bianchi, F.D., "Control of a Supercapacitor Energy Storage System for Microgrid Applications," IEEE Trans. Energy Convers. vol.28, no.3, pp.690,697, Sept. 2013

[18] Wickramasinghe Abeywardana, D.B.; Hredzak, B.; Agelidis, V.G., "Single-Phase Grid-Connected LiFePO4 Battery-Supercapacitor Hybrid Energy Storage System with Interleaved Boost Inverter," IEEE Trans. Power Electron, vol.30, no.10, pp.5591,5604, Oct. 2015.

[19] Tummuru, N.R.; Mishra, M.K.; S.Srinivas,., "Dynamic Energy Management of Hybrid Energy Storage System With High-Gain PV Converter," IEEE Trans. Energy Convers. vol.30, no.1, pp.150, 160, March 2015.

[20] Zhihui Ding; Chen Yang; Zhao Zhang; Cheng Wang; Shaojun Xie, "A Novel Soft-Switching Multiport Bidirectional DC-DC Converter for
Hybrid Energy Storage System," IEEE Trans. Power Electron. vol.29, no.4, pp.1595,1609, April 2014

[21] Garcia, P.; Garcia, C.A.; Fernandez, L.M.; Llorens, F.; Jurado, F., "ANFIS-Based Control of a Grid-Connected Hybrid System Integrating Renewable Energies, Hydrogen and Batteries," IEEE Trans. Ind. Informat. vol.10, no.2, pp.1107, 1117, May 2014.

[22] J. Zeng, W. Qiao, L. Qu, and Y. Jiao "An Isolated Multiport DC-DC Converter for Simultaneous Power Management of Multiple Different Renewable Energy Sources" IEEE J. Emerging Sel. Topics Power Electron. vol.2, no.1, pp. 70-78, Mar. 2014

[23] Junbiao Han; Solanki, S.K.; Solanki, J., "Coordinated Predictive Control of a Wind/Battery Microgrid System," IEEE J. Emerging Sel. Topics Power Electron. vol.1, no.4, pp.296,305, Dec. 2013.

[24] Jayasinghe, S.S.G.; Vilathgamuwa, D.M.; Madawala, U.K., "Direct Integration of Battery Energy Storage Systems in Distributed Power Generation," IEEE Trans. Energy Convers. vol.26, no.2, pp.677,685, June 2011.

[25] Fengqi Chang; Zedong Zheng; Yongdong Li, "A novel hybrid energy storage topology and its control algorithm," in Proc. 16th European Conf. on Power Electronics and Applications (EPE'14-ECCE Europe) vol., no., pp.1,9, 26-28 Aug. 2014.

[26] Takeda, K.; Takahashi, C.; Arita, H.; Kusumi, N.; Amano, M.; Emori, A., "Design of hybrid energy storage system using dual batteries for renewable applications," in Proc. IEEE Power and Energy Society (PES) General Meeting Conf. \& Exposition, vol., no., pp.1,5, 27-31 July 2014.

[27] Merei, G.; Magnor, D.; Leuthold, M.; Sauer, D.U., "Optimization of an off-grid hybrid power supply system based on battery aging models for different battery technologies," in Proc. $36^{\text {th }}$ IEEE Telecommunications Energy Conference (INTELEC), Sept. 28 -Oct. 2, 2014.

[28] Di Zhu; Siyu Yue; Yanzhi Wang; Younghyun Kim; Naehyuck Chang; Pedram, M., "Designing a residential hybrid electrical energy storage system based on the energy buffering strategy," in Proc. International Conf. on Hardware/Software Codesign and System Synthesis (CODES+ISSS), vol., no., pp.1,9, Sept. 29 2013-Oct. 42013.

[29] Mukherjee, N.; Strickland, D., "Control of Second-Life Hybrid Battery Energy Storage System Based on Modular Boost-Multilevel Buck Converter," IEEE Trans. Ind. Electron. vol.62, no.2, pp.1034,1046, Feb. 2015.

[30] Walker, G.R.; Sernia, P.C., "Cascaded DC-DC converter connection of photovoltaic modules," IEEE Trans. Power Electron. vol.19, no.4, pp.1130,1139, July 2004.

[31] Echeverria, J.; Kouro, S.; Perez, M.; Abu-Rub, H., "Multi-modular cascaded DC-DC converter for HVDC grid connection of large-scale photovoltaic power systems," in Proc. $39^{\text {th }}$ Annual Conf. Industrial Electronics Society, IECON, vol., no., pp.6999,7005, 10-13 Nov. 2013.

[32] Vighetti, S.; Ferrieux, J.; Lembeye, Y., "Optimization and Design of a Cascaded DC/DC Converter Devoted to Grid-Connected Photovoltaic Systems," IEEE Trans. Power Electron, vol.27, no.4, pp.2018,2027, April 2012.

[33] Montesinos-Miracle, D.; Massot-Campos, M.; Bergas-Jane, J.; Galceran-Arellano, S.; Rufer, A., "Design and Control of a Modular Multilevel DC/DC Converter for Regenerative Applications," IEEE Trans. Power Electron. vol.28, no.8, pp.3970,3979, Aug. 2013.

[34] A. Vogelsberger, T. Wiesinger, and H. Ertl, "Life-cycle monitoring and voltage-managing unit for DC-link electrolytic capacitors in PWM converters," IEEE Trans. Power Electron. vol. 26, no. 2, pp. 493-502, Feb. 2011.

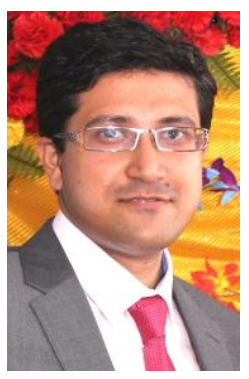

Nilanjan Mukherjee (S'12 - M'14) received the MEng degree (First Class) in Electrical Engineering from the Indian Institute of Science (IISc), Bangalore, India, in 2009. He completed his Ph.D. in Electronic Engineering with a speciation in Power Electronics from University of Aston, Birmingham, UK, in 2014.

From 2009 to 2011, he was with the Engineering Research Centre (ERC) of Tata Motors Ltd. where he was involved in power converter control in battery super-capacitor integration in Electric Vehicle drive train. He was with the Power Engineering and Power Electronics Research Group in Aston University as a postdoctoral research associate following his $\mathrm{PhD}$. He is currently working in the University of Birmingham, UK as a postdoctoral research fellow in Power Electronics. 
This article has been accepted for publication in a future issue of this journal, but has not been fully edited. Content may change prior to final publication. Citation information: DOI

10.1109/JESTPE.2015.2460334, IEEE Journal of Emerging and Selected Topics in Power Electronics

IEEE JOURNAL OF EMERGING AND SELECTED TOPICS IN POWER ELECTRONICS

$\mathrm{He}$ is a member of IEEE and IEEE industrial electronics society. He is actively engaged in reviewing committee in various leading IEEE/IET conferences and journals such as, IEEE transactions on Power Electronics, IEEE transactions on Industrial Electronics, IET Power Electronics and so on. His main research interests include the new generation power converter topologies especially multi-modular/modular multilevel converters and control strategies for energy storage, hybrid energy system integrations to the utility grid and traction drive systems.

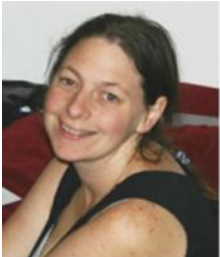

Dani Strickland has a degree from Heriot Watt University and a PhD from Cambridge University, UK in Electrical Engineering. She has worked for Eon, Sheffield University, Rolls Royce Fuel Cells PLC and is currently employed at Aston University as a lecturer.

Her main research interests include the application of power electronics to power systems. 